\title{
Detection and Monitoring of Tunneling-Induced Riverbed Deformation Using GPS and BeiDou: A Case Study
}

\author{
Wen Guo ${ }^{1}$, Guoquan Wang ${ }^{2, *}$, Yan Bao ${ }^{1, *}$, Pengfei Li ${ }^{1}$, Mingju Zhang ${ }^{1}$, Qiuming Gong ${ }^{1}$, \\ Rui Li ${ }^{3}$, Yang Gao ${ }^{4}$, Ruibin Zhao ${ }^{5}$ and Shuilong Shen ${ }^{6}$ \\ 1 The Key Laboratory of Urban Security and Disaster Engineering of China Ministry of Education, \\ Beijing University of Technology, Beijing 100124, China \\ 2 Department of Earth and Atmospheric Sciences, University of Houston, Houston, TX 77204, USA \\ 3 No. 6 Engineering Corporation Limited, China Railway 17th Bureau Group CO., LTD., Fuzhou 350000, China \\ 4 Structural Health Monitoring and Control Institute, Shijiazhuang Tiedao University, Shijiazhuang 050043, \\ China \\ 5 School of Geology and Geomatics, Tianjin Chengjian University, Tianjin 300384, China \\ 6 Department of Civil and Environmental Engineering, College of Engineering, Shantou University, Shantou, \\ Guangdong 515063, China \\ * Correspondence: gwang@uh.edu (G.W.); baoy@bjut.edu.cn (Y.B.); Tel.: +001-713-294-3224 (G.W.); \\ +86-136-1133-6182 (Y.B.)
}

Received: 7 June 2019; Accepted: 4 July 2019; Published: 8 July 2019

\begin{abstract}
Shield tunneling under rivers often requires monitoring riverbed deformations in near real-time. However, it is challenging to measure riverbed deformation with conventional survey techniques. This study introduces a comprehensive method that uses the Global Positioning System (GPS) of the USA and the BeiDou navigation satellite system (BeiDou) of China to monitor riverbed deformation during the construction of twin tunnels beneath the Hutuo River in Shijiazhuang, China. A semi-permanent GPS network with one base station outside the river and six rover stations within the river was established for conducting near real-time and long-term monitoring. The distances between the base and the rover antennas are within two kilometers. The network was continuously operating for eight months from April to December 2018. The method is comprised of three components: (1) Monitoring the stability of the base station using precise point positioning (PPP) method, a stable regional reference frame, and a seasonal ground deformation model; (2) monitoring the relative positions of rover stations using the carrier-phase double-difference (DD) positioning method in near real-time; and (3) detecting abrupt and gradual displacements at both base and rover stations using an automated change point detection algorithm. The method is able to detect abrupt positional-changes as minor as five millimeters in near real-time and gradual positional-changes at a couple of millimeters per day within a week. The method has the flexibility of concurrent processing different GPS and BeiDou data sessions (e.g., every 15 minutes, 30 minutes, one hour, one day) for diffident monitoring purposes. This study indicates that BeiDou observations can also achieve few-millimeter-accuracy for measuring displacements. Parallel processing GPS and BeiDou observations can improve the reliability of near real-time structural deformation monitoring and minimize false alerts. The method introduced in this article can be applied to other urban areas for near real-time and long-term structural health monitoring.
\end{abstract}

Keywords: BeiDou; change point detection; GPS; riverbed; shield; structural health monitoring; twin tunnels 


\section{Introduction}

Ground surface deformation monitoring during urban tunnel excavations is a common means for ensuring construction quality and safety, including the safety of people and equipment inside the tunnel and structures located on and near the ground surface. Conventional ground surface deformation monitoring involves the use of total stations, levels, inclinometers, and other devices that need to be deployed on the ground surface. However, it is inconvenient to utilize these conventional surveying techniques in open water areas, such as rivers and lakes. During the past three decades, numerous underwater transportation tunnels have been built in large cities in China. Underwater tunnel excavations often carry additional risks compared to ordinary tunnel excavations and could suffer severe consequences. Usually, shallow tunnels beneath rivers are driven in "soft" sediments comprising of silt, clay, sand, and gravel. Surrounding soil disturbances and tunnel deformations may lead to cracks and water infiltration, thus, threatening the safety of tunnel construction and operation. Accurate, continuous, long-term, and near real-time riverbed deformation monitoring has become a challenging topic for both researchers and engineers in urban tunneling. There is an urgent need for developing new techniques and methods for riverbed deformation monitoring.

Global positional system (GPS) techniques, global navigation satellite systems (GNSS) in general, have been frequently applied for studying dynamic behaviors of engineering structures during the past two decades [1-8]. Recently, GPS techniques have been applied for monitoring long-term stability and static deformation of engineering structures [9-11]. The deformation information is usually used to determine the state of the structure's health. Thus, the process of implementing GPS for detecting and monitoring the stability and deformation of engineering structures is a component of structural health monitoring (SHM), which focuses on assessing the health status of infrastructure using multiple techniques. SHM has become a cross-disciplinary research field encompassing fields such as civil engineering, surveying, remote sensing (ground-based, drone-based, satellite-based), mechanical engineering, structural dynamics, signal processing, computational hardware and software, data telemetry, smart sensors, machine learning and pattern recognition, as well as other fields yet to be defined [12-15]. The principal advantage of using satellite positioning techniques for SHM, as opposed to classical surveying techniques, is that they provide continuous and real-time (or near real-time) measurements in three directions.

There have been a large number of studies on GPS-based SHM systems over the last two decades, mostly utilizing kinematic GPS positioning techniques with a sampling rate of one sample per second $(1 \mathrm{~Hz})$ or higher to measure rapid movements of an GPS antenna, which indicate oscillations or kinematic deformations of engineering structures. Kinematic GPS has become a powerful tool for SHM. However, kinematic GPS techniques often fail to detect minor and gradual movement (deformation) of structures. This study focuses on the detection and monitoring of minor and gradual movements using static GPS positioning. The term "detection" primarily focuses on identifying abrupt positional-changes, which often requires near real-time positioning updates and decision making. The term "monitoring" focuses on slow and gradual positional-changes, such as settlement, uplift, tilt, and rotation of engineering structures. The distinction between the terms "abrupt displacement" and "gradual displacement" is somewhat nebulous because a field event always happens during a time period. For example, a positional shift continued for several hours may appear as an abrupt or instant step in daily-displacement time series; however, it may appear as a slope in hourly-displacement time series. For riverbed deformation addressed in this study, the monitoring is focused on detecting and confirming minor abrupt-deformations at a few millimeters and slow gradual-deformations at a few millimeters per week. The term "near real-time" indicates a time delay between the occurrence of an event in the field and the recognition of the event in the monitoring center. The difference between the terms "near real-time" and "real time" can be vague because it always takes a certain amount of time to identify and confirm an event even if the data transformation and processing can be conducted in seconds. 


\section{Project Overview}

The city of Shijiazhuang, being the capital of the Hebei Province, is $300 \mathrm{~km}$ away from Beijing. Similar to other large cities in China, Shijiazhuang also suffers significant mobility issues. To tackle these issues, a subway transportation network is under construction. The majority of the subway system is built underground. A segment of the Metro Line 1 was constructed beneath the Hutuo River (Figure 1a) during April-June 2018, which is a major river in north China that discharges into the sea through the Hai River. The Hutuo River is blocked by an overflow dam in the Shijiazhuang area and becomes a man-made lake, which is a part of the Urban Forest Park of Shijiazhuang. The water level is quite steady with an average water depth of $3 \mathrm{~m}$. Water movements in the shallow lake are usually minor. The length of the twin tunnels crossing the river is approximately $450 \mathrm{~m}$ (Figure $1 \mathrm{~b}$ ). Each tunnel was excavated by an earth pressure balance (EPB) shield machine. The shield is 6.24 $\mathrm{m}$ in diameter and $8.18 \mathrm{~m}$ in length. Shield driven tunneling, especially EPB tunneling, has been widely adopted in the construction of metro tunnels in China [16-19]. It took approximately $50 \mathrm{~min}$ for the shield machine to bore $(\sim 20 \mathrm{~min})$ and install $(\sim 30 \mathrm{~min})$ one concrete lining if the process was smooth. The width of the tunnel lining with segmental rings is $1.2 \mathrm{~m}$. However, the operation of boring and lining installation was often disturbed by various reasons. The shield machine bored 20 $\mathrm{m}$ on its most productive day, and $100 \mathrm{~m}$ during its best week. The time that the 8.18-m-long shield machine passed GPS sites varied from 6.5 to $34 \mathrm{~h}$ (Table 1).

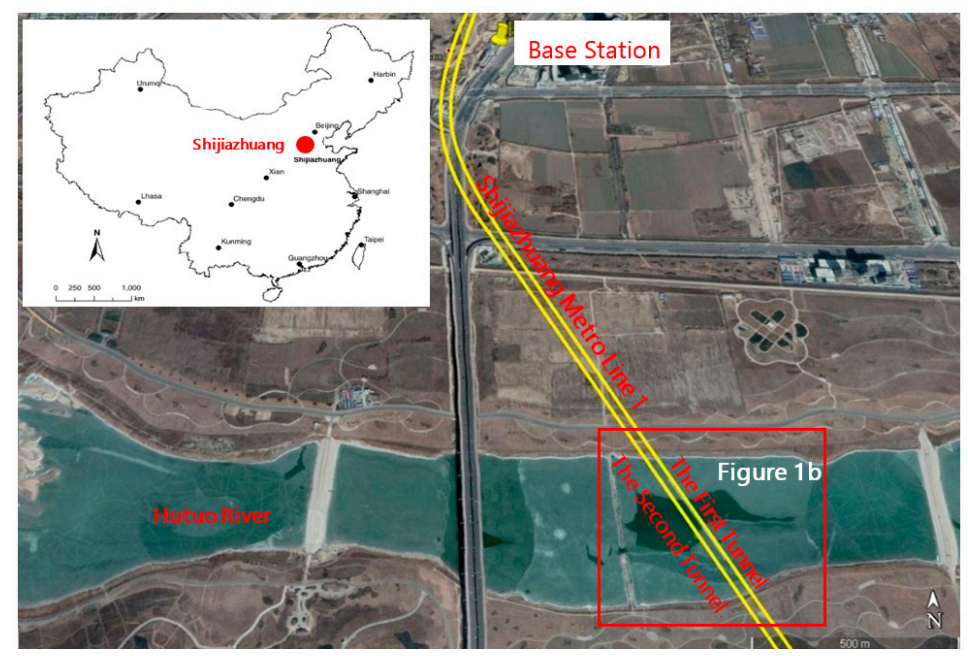

(a)

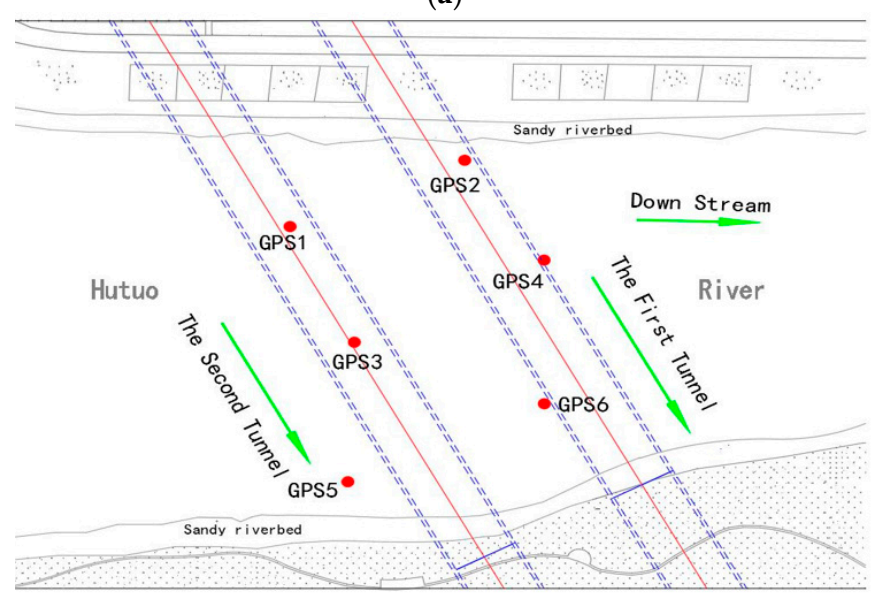

(b)

Figure 1. (a) A map showing the locations of the twin-tunnel project and the reference Global Positioning System (GPS) station in Shijiazhuang; (b) a sketch showing the locations of six rover GPS stations within the Hutuo River. 
The distance between the centerlines of the twin tunnels is $15.2 \mathrm{~m}$ (Figure 2a). The average depth of the tunnel centerline is $17 \mathrm{~m}$ below the riverbed, slightly less than three times of the diameter of the tunnels. The outside and inside diameters of the tunnels are $6 \mathrm{~m}$ and $5.4 \mathrm{~m}$, respectively (Figure 2a,b). The excavations were conducted mainly in heterogeneous alluvial deposits (see Figure 2c) composed of silty clay and sand deposits. The groundwater level in the Shijiazhuang area is about 40 $\mathrm{m}$ below the land surface [20]. Thus, the excavation sections of the tunnels are approximately $20 \mathrm{~m}$ above the regional groundwater level.

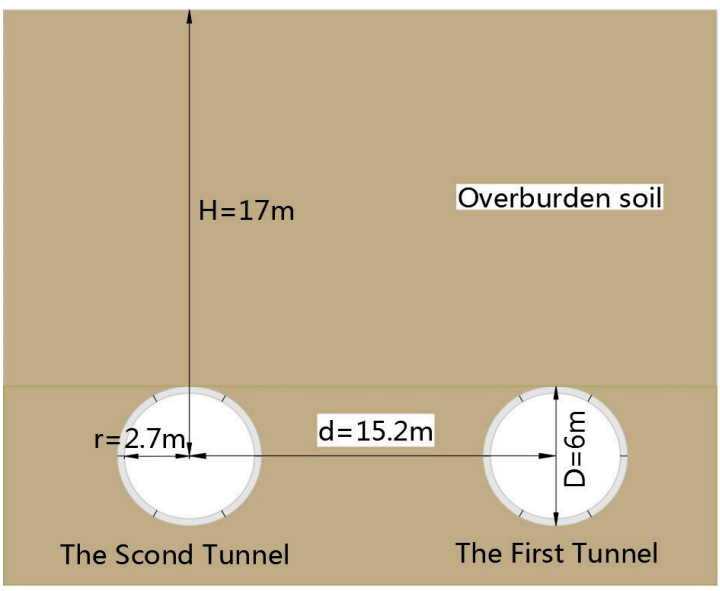

(a)

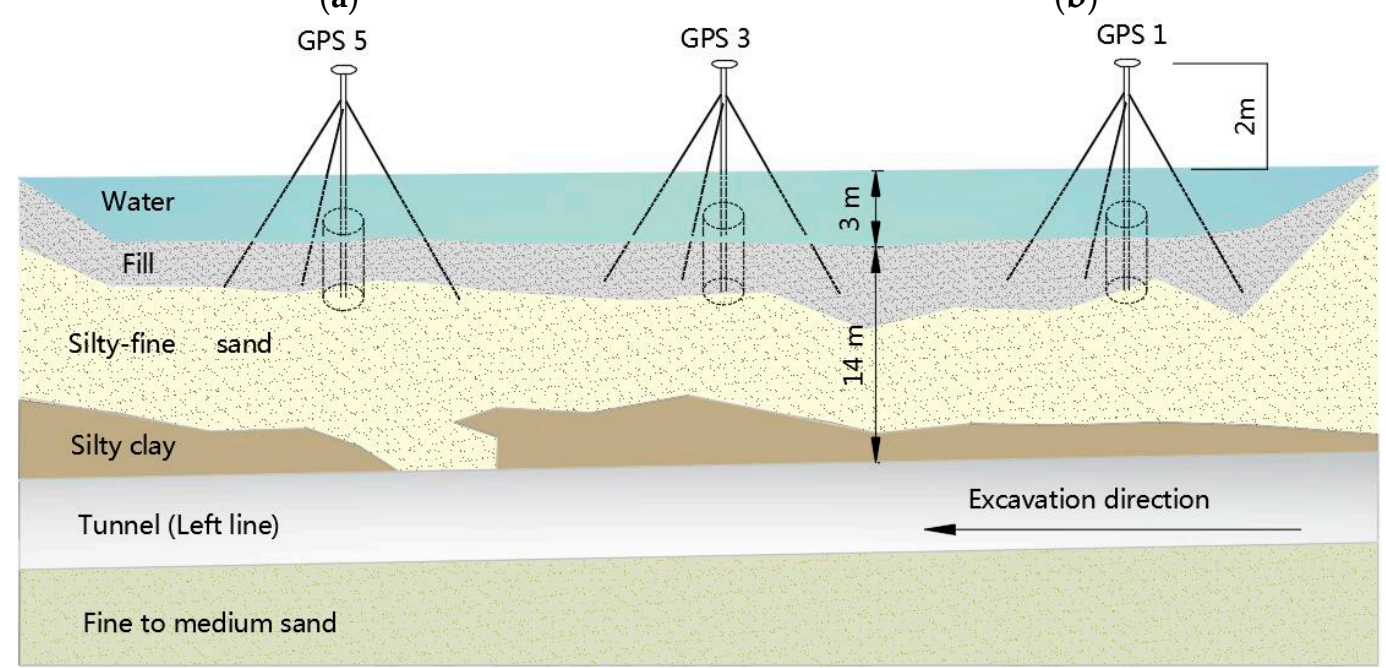

(c)

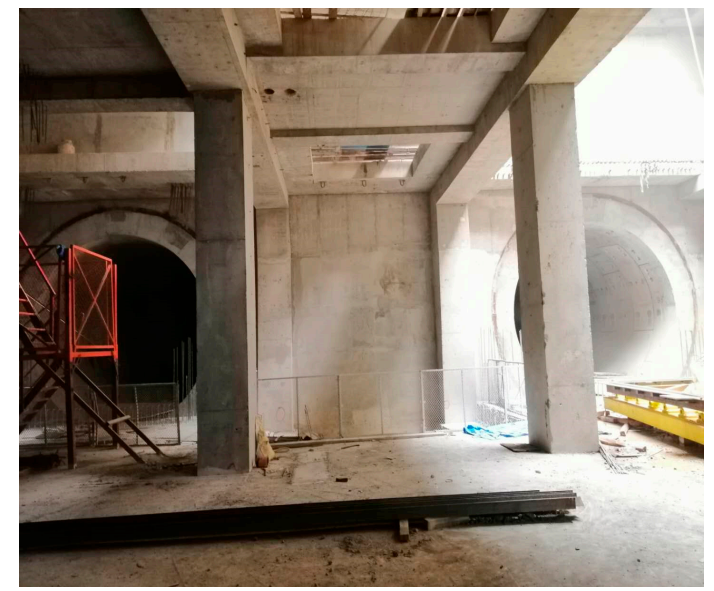

(b)

Exavation direction

Figure 2. (a) A sketch illustrating the major parameters of the twin tunnels; (b) a site photo showing the twin tunnels; (c) a sketch illustrating the GPS-antenna monuments above the centerline of the second tunnel.

Table 1. Date and time that the shield machine passed each rover GPS.

\begin{tabular}{|c|c|c|c|c|c|}
\hline & Rover Stations & Distance to Base (m) & $\begin{array}{l}\text { Shield-Head Arriving } \\
\text { (Beijing Time *) }\end{array}$ & $\begin{array}{l}\text { Shield-Tail Leaving } \\
\text { (Beijing Time *) }\end{array}$ & $\begin{array}{l}\text { Total Time Passing } \\
\text { the Site }\end{array}$ \\
\hline \multirow{3}{*}{ First Tunnel } & GPS2 & 1679.584 & 16:16, April 28 & 12:28, April 29 & $20 \mathrm{~h}$ \\
\hline & GPS4 & 1794.432 & 05:13, May 04 & 13:44, May 04 & $8.5 \mathrm{~h}$ \\
\hline & GPS6 & 1917.414 & $12: 25$, May 14 & 16:17, May 15 & $28 \mathrm{~h}$ \\
\hline \multirow{3}{*}{ Second Tunnel } & GPS1 & 1672.586 & 10:14, May 26 & 17:08, May 26 & $7 \mathrm{~h}$ \\
\hline & GPS3 & 1795.117 & 02:56, Jun 03 & 12:40, Jun 04 & $34 \mathrm{~h}$ \\
\hline & GPS5 & 1912.585 & 21:10, Jun 12 & 03:44, Jun 13 & $6.5 \mathrm{~h}$ \\
\hline
\end{tabular}

* Beijing time is $8 \mathrm{~h}$ ahead of the Universal Time Coordinated (UTC). 
Owing to the fact that this project is the first shield driven tunnel beneath the Hutuo River in Shijiazhuang, a significant concern regarding the riverbed deformation and tunneling safety occurred during the excavations. Based on our experiences from previous GPS monitoring projects [21-25], we established a GPS monitoring network with one base station (BASE) and six rover stations named GPS1, GPS2, GPS3, GPS4, GPS5, and GPS6 (Figure 1b). The base station was installed at the headquarters of the project, about two kilometers away from the river (Figure 1a). The antenna pole of the base station was arched on a concrete block fixed on the floor of a park lot (Figure 3a). The antenna monument was further stabilized by three steel reinforced bars. There are tall trees, metal fences and roofs, and cars close to the antenna. Obviously, this site is not perfect for a continuously operating reference station (CORS). However, it is a security site and is able to provide reliable alternating current (AC) for power supplies and fast internet connection for data communication, which are critically important for real-time (or near real-time) monitoring. In practice, the selection of a reference site always needs to balance many issues, such as distances to rovers, multipath effects, power supplies, data communication, and site security.

These six rover stations were installed within the river along the centerlines of the twin tunnels as exhibited in Figure 3b. The antenna poles are galvanized steel pipes with an outside diameter of $11 \mathrm{~cm}$ and a length of $5.5 \mathrm{~m}$. Each antenna pole was built into a cast-in-place concrete cylinder. The concrete cylinder was constructed by first sinking a heavy steel tank $(0.8 \mathrm{~m}$ in diameter and $1.2 \mathrm{~m}$ in height, Figure 2c) into the silt and clay below the water, and then pouring concrete into the tank. Each antenna pole was further enforced by three to four reinforcing bars $(2.5 \mathrm{~cm}$ in diameter $)$ as shown in Figure 3b. The rover stations were installed approximately three weeks before the first shield arrived to the river bank. The Trimble NetR9 GNSS receivers and Zephyr Geodetic II antennas were equipped on the base and rover stations. Specific parameters of the GNSS antennas and receivers are available at the website of the manufacturer (https://www.trimble.com/Infrastructure/Trimble-NetR9.aspx).

The GPS units were configured to track GPS and BeiDou satellites. A solar power system and a cellular data communication system were equipped at each rover site (Figure 3b). The right line was excavated about one month earlier than the left line. Therefore, the right line is called the first tunnel, and the left line is called the second tunnel. GPS2, GPS4, and GPS6 were installed along the centerline of the first tunnel; GPS1, GPS3, and GPS5 were installed along the centerline of the second tunnel (Figure 1b).

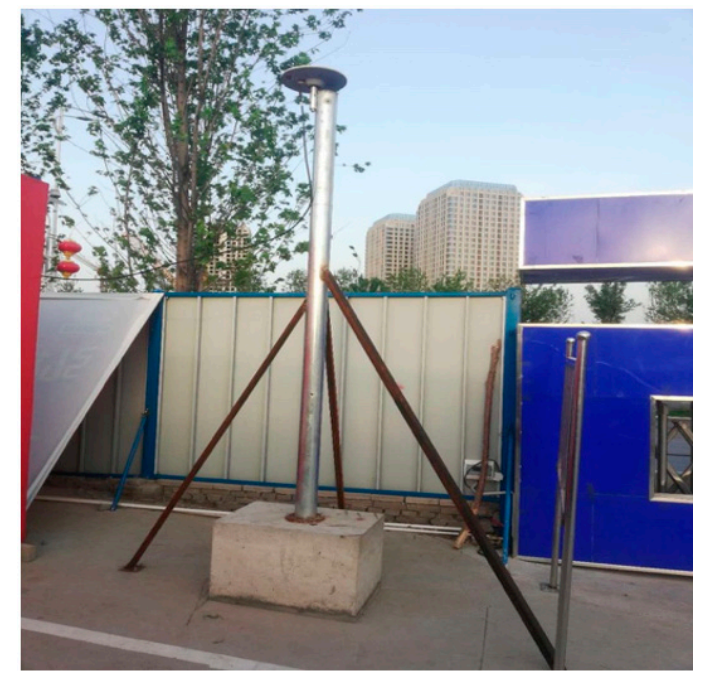

(a)

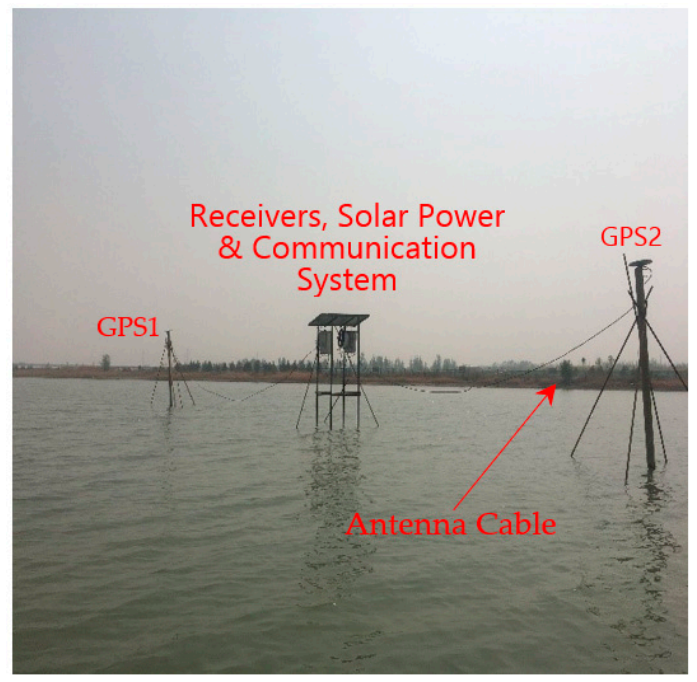

(b)

Figure 3. (a) The antenna monument of the reference GPS station (BASE); (b) the antenna monuments of rover stations GPS1 and GPS2, and the power and real-time data communication system. 


\section{Methods}

\subsection{GPS Data Processing}

Survey-grade GNSS receivers record satellite signals (e.g., time, phase centers, pseudoranges, signal-to-noise ratios), but cannot provide centimeter-accuracy positions directly. GPS observations need to be carefully processed with supplementary information to achieve centimeter-precision positions, in turn, millimeter- or submillimeter-accuracy displacements for SHM purposes. GPS data can be processed in a kinematic mode or a static mode. Numerous algorithms have been developed for both kinematic and static processing for different application purposes. In short, kinematic algorithms solve a position epoch by epoch, while static algorithms solve a position using a period of observations to obtain the best estimate of the position. Kinematic positioning is used for studying dynamic displacements/deformations of civil engineering structures, such as vibrations of long-span bridges and high-rise buildings under wind and earthquakes. Static positioning techniques take advantage of long occupation times (from a few minutes to a day) to achieve high-accuracy positional time series to capture rapid and gradual positional-changes. In general, kinematic GPS processing may result in more outliers compared to static positioning, though kinematic positioning with short baselines can also achieve millimeter accuracy [26,27]. For the riverbed deformation monitoring, we will target on minor and gradual positional-changes rather than rapid positional-changes. Therefore, static rather than kinematic positioning methods are employed in GPS and BeiDou data processing in this study.

The accuracy of GPS-derived displacements does not solely rely on GPS equipment (antenna and receiver), but mostly depends on how the data is collected and processed. Typically, there are two approaches to achieve high-precision GPS positioning solutions: Relative positioning and absolute positioning. Detailed introductions of these two methods are presented in our previous publications [28-32]. In general, the accuracy and precision of GPS-derived positions have been improved dramatically over the past two decades due to the advances in GPS hardware, software, and reference frames $[29,33]$.

The relative positioning method is known as carrier-phase double-difference (DD), which uses simultaneous observations from two GPS units to obtain relative positions of one station (rover) with respect to another one (base). The displacements of the rover can be derived from the relative positional time series. The DD method inherits high accuracy from the fact that closely spaced GPS units share significant common errors and biases. Errors introduced by troposphere, ionosphere, satellite orbits, satellite and receiver clocks could be significantly mitigated by the differential processing with short baselines (e.g., $<10 \mathrm{~km}$ ). Because the number of common errors decreases with increasing antenna-to-antenna distance, the performance of the differential method highly depends on the length of the baseline. DD processing is often employed as a core processing engine for network processing that includes multi-base and multi-rover stations. The size of most engineering structures is within a couple of kilometers, such as dams, bridges, and high-rise buildings. One or more reference stations can be installed adjacent to the monitoring object. Short baselines within a few kilometers would result in substantially high repeatability (precision) of the relative positions, in turn, resulting in high-accuracy displacement measurements. Sub-millimeter accuracy, the root-mean-square (RMS) of the residuals of displacements, was achieved in our previous landslide monitoring project using 24-hour continuous GPS observations [22]. The DD method has been frequently applied for detecting instant deformation of ground surface and engineering structures due to its operational simplicity and its ability to achieve millimeter-accuracy displacements.

The absolute positioning method uses a single ground GPS station to achieve high-precision positioning, and in turn, high-accuracy displacements and site velocities. Precise point positioning (PPP) is a typical absolute positioning method that has been widely applied in the geodesy community for plate tectonic studies and natural hazards (landslides, subsidence) monitoring. PPP techniques use un-differenced dual-frequency pseudorange and carrier-phase observations, precise satellite orbits and clock information, high-fidelity error modeling, and other information to determine 
the position of a stand-alone GPS antenna [34]. Compared to the DD method, the PPP method has not been widely applied in civil engineering and land surveying communities. There are various reasons for this. One primary reason is that the majority of structural-monitoring projects focus on short-term monitoring during construction rather than long-term post-construction monitoring. With the realization of the importance of long-term SHM, PPP positioning will be increasingly applied in the field of civil and surveying engineering.

The GAMIT/GLOBK software package (Version 10.7) is employed for DD processing [35], and the GIPSY-OASIS (V6.4) software package is employed for PPP processing [36]. The GIPSY-OASIS software package employs a single-receiver phase ambiguity-fixed PPP method for its static positioning. According to Wang et al. [37], the GIPSY PPP daily solutions retain 2 to $4 \mathrm{~mm}$ horizontal RMS-accuracy (repeatability) and 7 to $9 \mathrm{~mm}$ vertical RMS-accuracy in North China. Since the baselines are extremely short $(<2 \mathrm{~km})$ for the riverbed monitoring project, we only use the L1 observations for DD processing. We found that for baselines within a couple of kilometers, using L1-only observations can result in a higher precision (repeatability) of relative positions than using the L1 and L2 combined observations [22].

Both DD and PPP methods can be employed in post-processing or near real-time processing. For near real-time DD processing, the information recorded by the base and rover GPS receivers is sufficient to solve the relative position of the rover. For PPP processing, many publicly available data sets are required, such as precise estimates of the GPS satellite orbit and clock offsets, earth orientation, transmitter antenna calibration, and wide lane and phase bias (WLPB) estimates obtained from a global network of ground GPS stations. For PPP processing employed in the GIPSY software package, those products are available to the public through the Jet Propulsion Laboratory (JPL) as three product lines: Ultra-rapid, rapid, and final according to the latency in availability (https://gipsy-oasis.jpl.nasa.gov). All products span $30 \mathrm{~h}$. The final products are available after ten days. The rapid products are available the next day at 16:00 Universal Time Coordinated (UTC), which is a delay of approximately $16 \mathrm{~h}$ after the end of the previous observation day. The ultra-rapid products are available in near real-time and are updated every hour. The accuracy of the products improves with longer latencies. All three products can be automatically fetched for automated processing. The accuracy ( 1 sigma) of the ultra-rapid, rapid, and final orbits are 5,3.5, and $2.5 \mathrm{~cm}$, respectively. According to our previous investigations on GPS datasets collected in Beijing [11], the RMS-accuracy of daily PPP solutions corresponding to the rapid orbit products is almost identical to the RMS-accuracy obtained from the final orbit products. The RMS-accuracy of the daily PPP solutions corresponding to the ultra-rapid products agrees with the accuracy corresponding to the final products within a one-millimeter level. The JPL rapid products are used in this study to simulate near real-time monitoring.

Figure 4 depicts the comparisons of three-component displacement time series of GPS1 derived from daily DD and PPP solutions. GPS provides displacement measurements in three directions: North-south (NS), east-west (EW), and up-down (UD) directions. The DD solutions are referred to the base station. The baseline is approximately $1.7 \mathrm{~km}$. The PPP solutions are referred to a stable regional reference frame. A smoothed trend line is also plotted for each time series. The trend is obtained by a moving-average filter with a sliding window of 11 measurements, current point plus 5 points before and after the current point. It is clear that the PPP solutions retain a larger scatter than the DD solutions. Further analysis indicates that the RMS-accuracy of the PPP solutions was approximately $3 \mathrm{~mm}$ in the horizontal directions and $7 \mathrm{~mm}$ in the vertical direction; the DD solutions achieved 1.5-mm RMS-accuracy in the horizontal directions and $2.5-\mathrm{mm}$ in the vertical direction (Figure $4 \mathrm{~b}, \mathrm{~d}, \mathrm{f}$ ). 

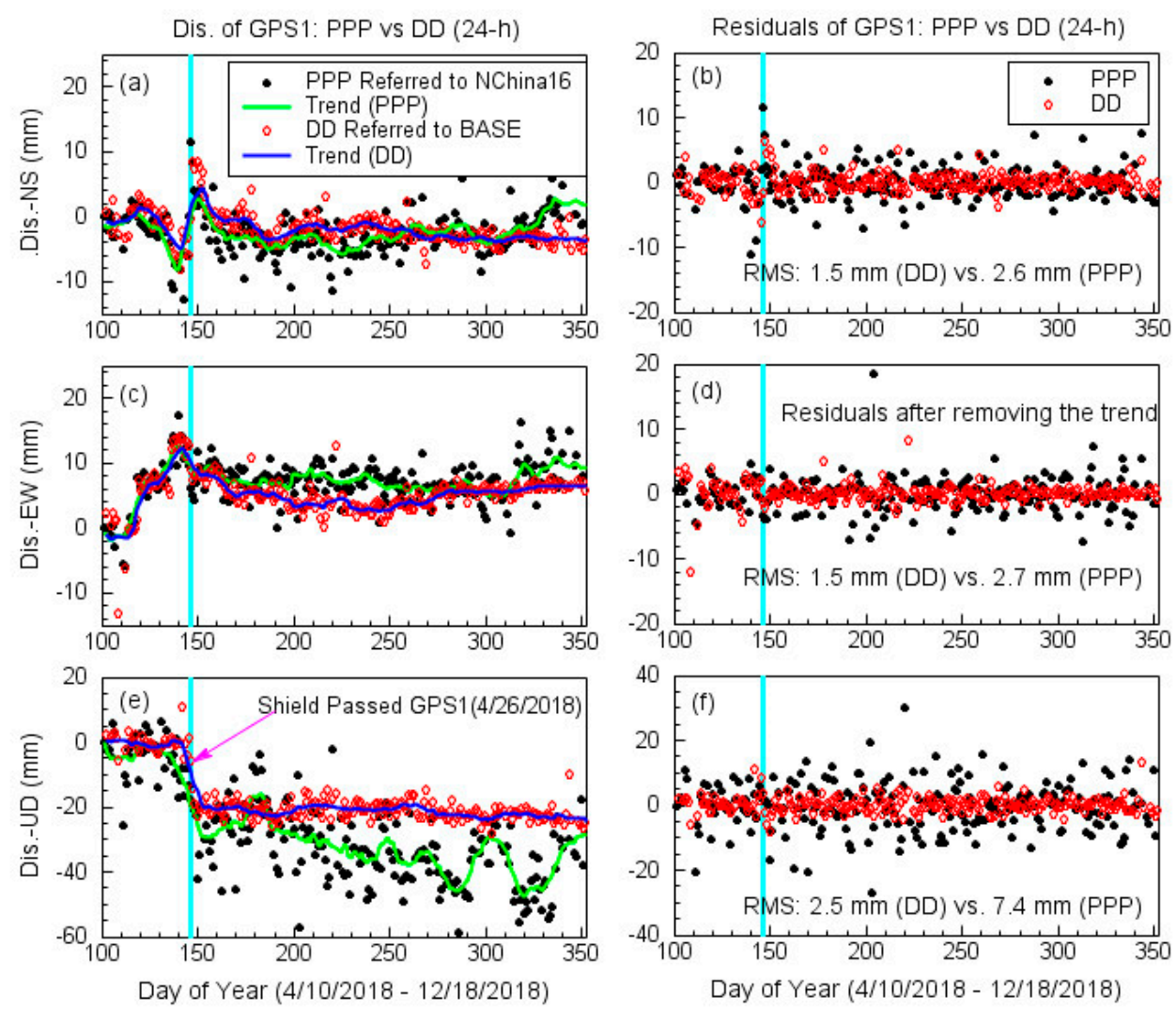

Figure 4. Three-component displacement time series at GPS1 derived from daily Precise Point Positioning (PPP) and Double Difference (DD) solutions. The PPP solutions are aligned with a stable regional reference frame (NChina16); the DD solutions are referred to the base station (BASE). Trend lines are obtained by applying a moving-average (unweighted) with a sliding window on the GPS-derived displacements. The width of the sliding window is 11 points comprised of the current point and five points before and after the current point.

\subsection{Monitoring the Stability of the Base Station}

In general, DD processing with short baseline is able to achieve higher displacement-accuracy than PPP processing. However, DD processing requires one extra station (reference) to be continuously operated in the field during the entire monitoring period. The stability and data quality of the reference station will therefore directly affect the accuracy of the displacement measurements at rover stations. It can be a challenge to keep a reference station strictly stable for several months to years in the field, particularly in urban environments. Instant movements at a few millimeters or gradual movements at a couple of millimeters per week at a reference site could be unnoticed. Thus, the unnoticed movement at the reference site could propagate to the positions of rovers and lead to a wrong interpretation of the stability of the monitoring objects. For real-time monitoring, it could even lead to false alerts. So, the stability of the base station needs to be continuously monitored.

The PPP method solves the position of an antenna with one stand-alone GPS station without directly using observations from other ground stations. The positions are referred to a global reference frame that defines the orbit of satellites. Currently, the International GNSS Service (IGS) Reference Frame 2014 (IGS14) is utilized to define the satellite orbits by IGS [38]. In general, a global reference frame is realized by minimizing the overall secular horizontal velocities of hundreds of selected stations distributed worldwide. As a result, linear velocities at GPS sites referred to a global reference frame are often dominated by long-term tectonic drifts. Minor structural deformation could be obscured by the underlying plate motions with respect to the global reference frame [32]. A stable regional or local reference frame is needed to exclude the effects of the plate motions. In this study, 
we transform the IGS14 coordinates to the Stable North China Reference Frame 2016 (NChina16), which was established from over six years of observations from 15 continuous operating reference stations (CORS) fixed on the North China Craton [37]. The frame stability of NChina16 is within $1 \mathrm{~mm} /$ year.

Figure 5 depicts the daily PPP solutions of the base station with respect to NChina16. The antenna monument of the base station was reinforced on 17 April 2018 (day of the year: 107) by welding three legs (Figure 3a). The field reinforcement was handled in a cautious way to avoid disturbing the base antenna. However, an abrupt horizontal displacement indeed happened. The daily displacement time series clearly indicate that the reinforcement caused a 0.8-cm movement toward the south (Figure 5a) and a 1.3-cm movement toward the west (Figure $5 \mathrm{~b}$ ). The disturbance in the vertical direction is not so obvious partially because of large scatter of the vertical displacement time series (Figure $5 \mathrm{c}$ ). The unexpected positional shift will be unnoticed without continuous monitoring using the absolute positioning method. An unnoticed positional change at the base station will lead to an abrupt step in the positional time series of rover antennas.
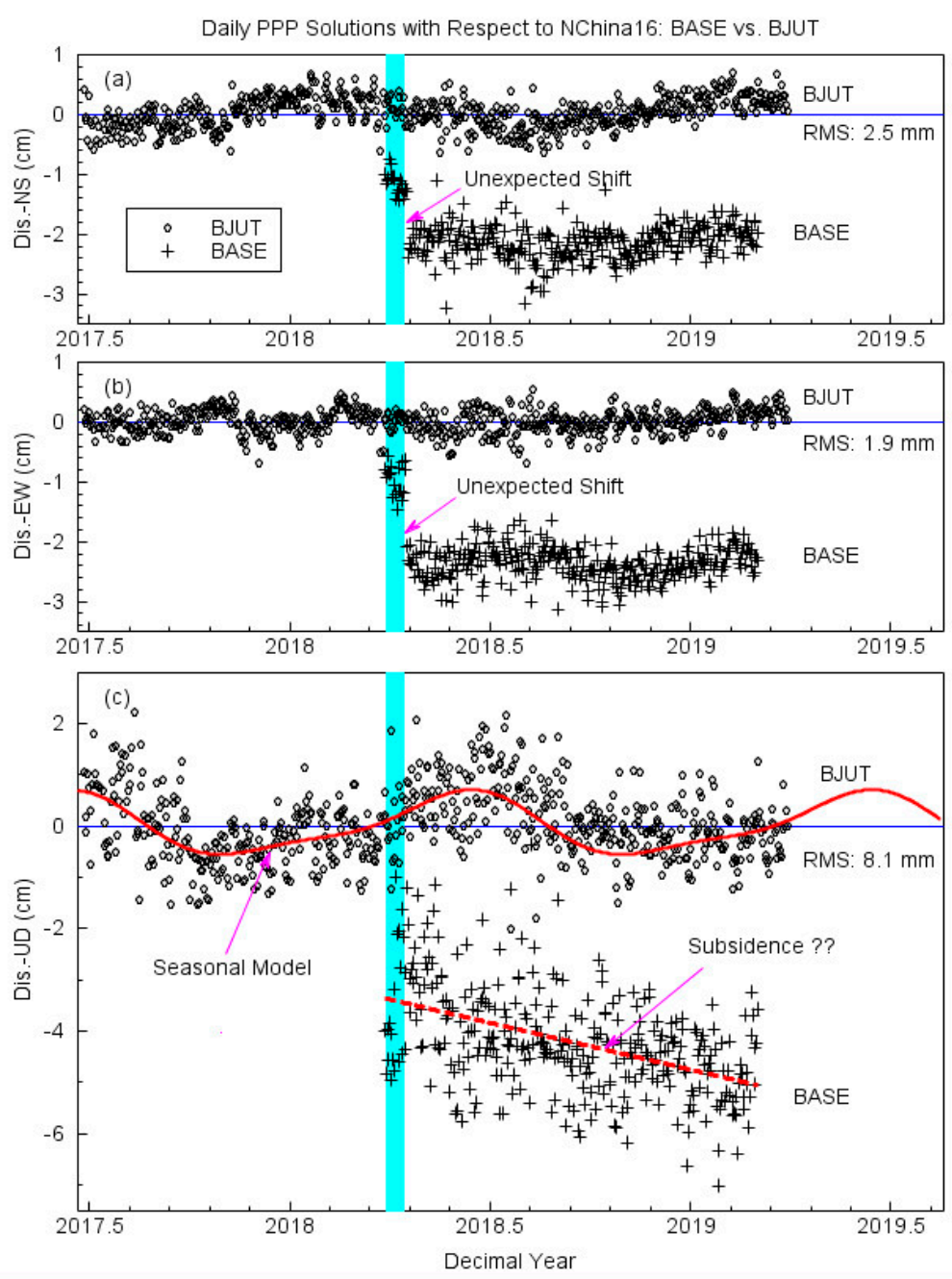

Figure 5. Plots depicting the stability of the base GPS (BASE) using Precise Point Positioning (PPP) processing, a stable regional reference frame, and a seasonal model (vertical) of ground deformation. The displacement time series of BJUT are illustrated for comparisons. (a) Displacement time series of the North-South (NS) direction; (b) displacement time series of the East-West (EW) direction; (c) displacement time series of the Upper-Down (UD) direction. The shaded period indicates the GPS-derived relative positions before the enforcement of the antenna monument of the base GPS on 17 April 2018. 
The vertical displacement time series of the base station (Figure $5 c$ ) indicates a linear trend toward the downward direction. The same downward trend was presented by the PPP solutions of GPS1, as shown in Figure 4e. In order to assess the long-term stability of the base station, we also investigated daily PPP solutions of a permanent GPS station (BJUT) outside of the study area. BJUT is located on the campus of the Beijing University of Technology, which is approximately $250 \mathrm{~km}$ away from the base GPS station. The displacement time series of BJUT depicts seasonal movements of the ground surface in both horizontal and vertical directions. The seasonal up and down of the ground surface is substantial with peak-to-trough amplitude of over two centimeters. GPS-derived positional time series are well known to have periodic variations attributed to a combination of annual and half-annual cyclical sinusoids [39]. A seasonal ground deformation model (vertical) was developed to simulate GPS-derived ground displacement time series in North China [37], which can be described as:

$$
\text { Seasonal }_{U D}(\mathrm{t})=-0.35 \times \cos (2 \pi \mathrm{t})+0.45 \times \sin (2 \pi \mathrm{t})+0.1 \times \cos (4 \pi \mathrm{t})-0.13 \times \sin (4 \pi \mathrm{t}),
$$

where $t$ is decimal year. The unit of the seasonal motion is in centimeters. The vertical oscillations could be a combination of true seasonal up and down movement of ground surface and certain periodic errors associated with the data modeling used in PPP processing. The red line in Figure $5 \mathrm{c}$ represents the seasonal model. The vertical displacement time series of BJUT agrees considerably well with the regional seasonal model. It turns out that the downward movement of the base GPS from April to December is coincident with the down-term of the seasonal ground movements. It is difficult to recognize seasonal motions from a dataset shorter than one year. Figures 4 and 5 reveal that a regional stable reference frame and a seasonal ground surface deformation model are critically important for assessing the long-term stability of reference stations.

\subsection{Change Point Detection}

During urban tunneling, the main objective of ground deformation monitoring is to detect abrupt and gradual displacements in time to prevent damage to surface structures and utilities. Continuous GPS observations and near real-time data processing are able to provide near real-time measurement streams in three directions. Abrupt positional changes at a few centimeters can be easily detected by eye from the incoming displacement time series. However, minor abrupt-displacements (steps) at a few millimeters and slow gradual-displacements, may go unnoticed because they are of similar size to the data noise and the step may be hidden by the noise. An automatic signal processing algorithm is needed to aid in detecting abrupt as well as gradual positional changes from the incoming displacement time series.

The step detection problem occurs in multiple scientific and engineering contexts. In signal processing, this is usually considered a special case of the statistical method known as change point detection (CPD). CPD has been studied for several decades in the fields of data mining, statistics, digital signal process, and computer science. Numerous CPD-algorithms have been developed for different application purposes [40,41]. CPD algorithms are traditionally classified as "online" or "offline". Online CPD algorithms run concurrently with the data processing (measuring) and analyze each measurement as it becomes available with a goal of detecting a change point as soon as possible after it occurs, ideally before the next measurement arrives. In contrast, offline algorithms consider the entire dataset at once, and look back in time to recognize where or when the change occurred. For near real-time monitoring purposes, an online algorithm is needed.

We tested several online CPD algorithms and found that a backward moving-average (boxcar) filter with a sliding-window works well to detect abrupt displacements in GPS-derived displacement time series. The averaging process can improve the signal-to-noise ratio in the time domain by passing long-period power (real displacements) and by attenuating short-period power (mostly noise, outliers). For the backward filtering, the sliding window consists of the current point and $n$ points before the current point. The value at the current point is replaced with the mean value of the points in 
the current window. The width of the sliding window $(n)$ should be large enough to minimize errors to represent the overall state yet small enough to still enhance the step caused by a minor positional change. A conceptual backward moving-average filter can be illustrated in the following. For incoming data stream:

$$
X=\{x(1), x(2), \ldots, x(n), x(n+1), \ldots, x(i)\},
$$

the backward-filtered data stream can be described as

$$
f(i)=\sum_{j=0}^{n} x(i-j) /(n+1) .
$$

The advantage of the backward filtering is that it does not require any new measurements. However, a potential incoming step can be degraded by its adjacent previous measurements. Thus, it could be hard to identify the exact change point in time if the change is minor. In order to detect the exact change point in near real-time, we further applied a forward moving-average filter. For the forward filtering, the sliding-window consists of the current point and $n$ points that come after the current point. So, the value of the point needs to wait for $n$ new measurements to be replaced with the mean value. The forward filter can be written as:

$$
f(i)=\sum_{j=0}^{n} x(i+j) /(n+1) .
$$

The forward filter is offline by $n$ points. The sensitivity of the CPD depends on the window size. Although small windows would be able to detect changes in a shorter time compared to larger windows, it may fail to detect minor changes. We find that a window size of five measurements works well for both daily and hourly displacement time series presented in this study.

Figure 6 illustrates the implementation of the CPD algorithm in detecting the abrupt horizontal displacement occurred at the base station, as illustrated in Figure 5a,b. In a scenario of near real-time monitoring, three data streams (in each direction) are coming to the monitoring center: GPS-measured displacement (black), backward-filtered displacement (green), and forward-filtered displacement (red). On day 107, the incoming measurement in the NS direction is normal (Figure 6a), while the measurement in the EW direction shows a one-centimeter shift to the west (Figure 6b). The instant shift in the EW component can be a noisy measurement (often called an outlier) or a sudden deformation of the riverbed. The key of the near real-time monitoring is to clarify the shift: An outlier or a field event, as soon as possible. In statistics, an outlier is a data point that differs significantly from other observations. A measurement that is three times larger than the standard deviation $(\sigma)$ of the whole time series is often called an outlier in the geodesy research community [42]. On day 108, the incoming measurements in both NS and EW directions show a shift of approximately one centimeter toward the south and the west; the backward-filtered streams indicate a slight turn toward the south (Figure 6a) and the west (Figure 6b). Meanwhile, the forward-filtered stream is just updated on day 103, which also shows the southward and westward turns. Combining these three data streams in both NS and EW directions, the monitoring person may be able to realize that a horizontal positional change has happened. On day 111, the backward-filtered stream indicates a rapid positional-change; the forward-filtered stream is updated on day 106, which also shows a positional change. So far, a positional change has been identified with a high confidence. However, the exact initial change time (point) is still not very clear. On day 114, the backward-filtered stream turns flat, the forward-filtered stream is updated on day 109, which also shows a turned corner. The date that is aligned with the corners of the backward and forward-filtered streams indicates the change point, which is between days 107 and 108. According to our field notes, the reinforcement of the base station was conducted on the afternoon of day 107. 

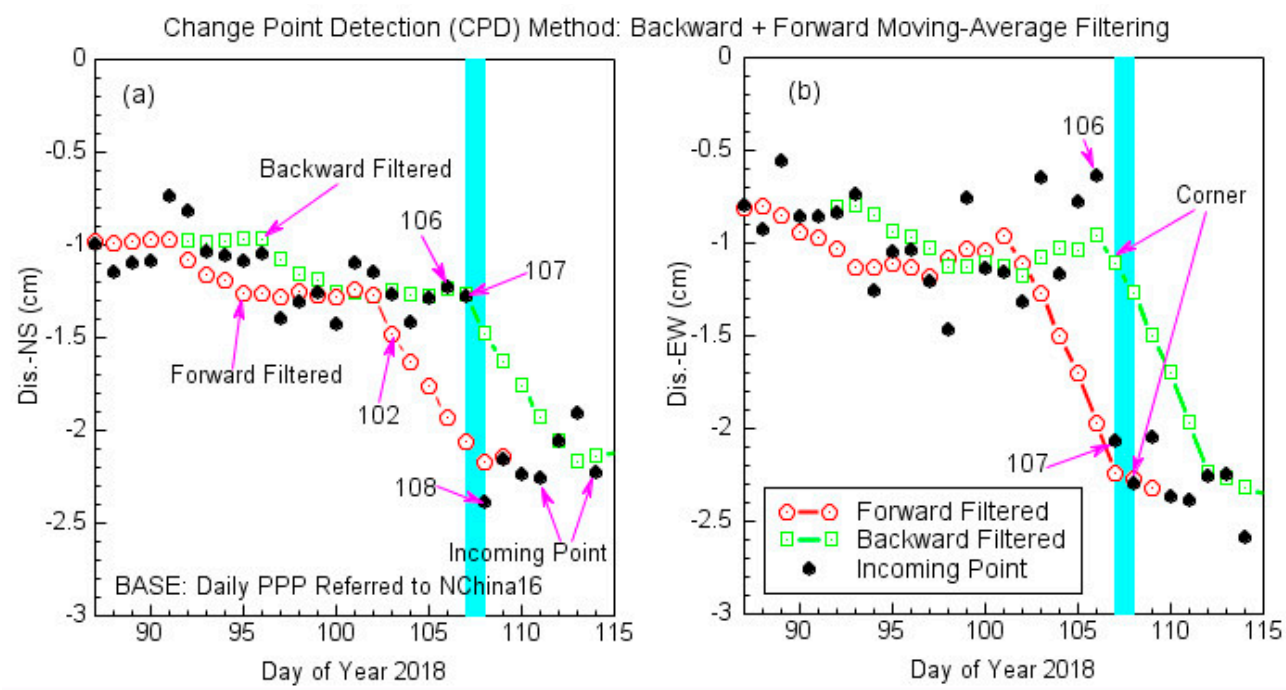

Figure 6. Plots illustrating the implementation of the change point detection (CPD) algorithm in near real-time monitoring. (a) Displacement time series of the North-South (NS) direction; (b) displacement time series of the East-West (EW) direction. The algorithm combines a backward moving-average filter and a forward moving-average filter. The change point aligns with the turn points (corners) of the backward-filtered and forward-filtered data streams.

In order to detect riverbed deformation in time, DD processing can be conducted with shorter data sessions, such as every $10 \mathrm{~min}$, every $30 \mathrm{~min}$, and every hour. Figure 7 illustrates the three-component hourly displacement time series of GPS1 and the filtered data streams during one month from 1 May to 1 June 2018. The CPD algorithm was implemented on the incoming displacement streams. Visually, two riverbed deformational events happened at GPS1 during this period. The first displacement happened during days 136 to 137, and the second one happened during days 146 to 149 . Figure $7 \mathrm{~b}, \mathrm{e}, \mathrm{h}$ exhibit the first event, an abrupt horizontal displacement of $10 \mathrm{~mm}$ toward the southeast, which is approximately 10 days before the shield passed GPS1 (day 146, 26 May 2018). The positional change can be precisely detected by the CPD algorithm, as shown in Figure 7e. It is concluded that the abrupt displacement started at 3 PM (UTC) on day 136 (16 May 2018). Figure 7c,f,i exhibit the second event, a gradual displacement that was occurring in all three directions. This event started several hours before the shield arrived at GPS1 and continued for over two days after the shield passing the site. It took approximately $7 \mathrm{~h}$ (02:00-09:00, day of year 146, UTC) for the 8.2-m-long shield to pass this site. The gradual displacement continued approximately two days from days 146 to 147 with average velocities of 10, 3 and $6 \mathrm{~mm} /$ day in the NS, EW and vertical directions, respectively. Figure 7 indicates that the CPD algorithm works well to identify abrupt positional changes in near real-time. However, it always takes time to recognize gradual positional changes. Continuous and long-term monitoring is essential for identifying and confirming slow and gradual positional changes. 

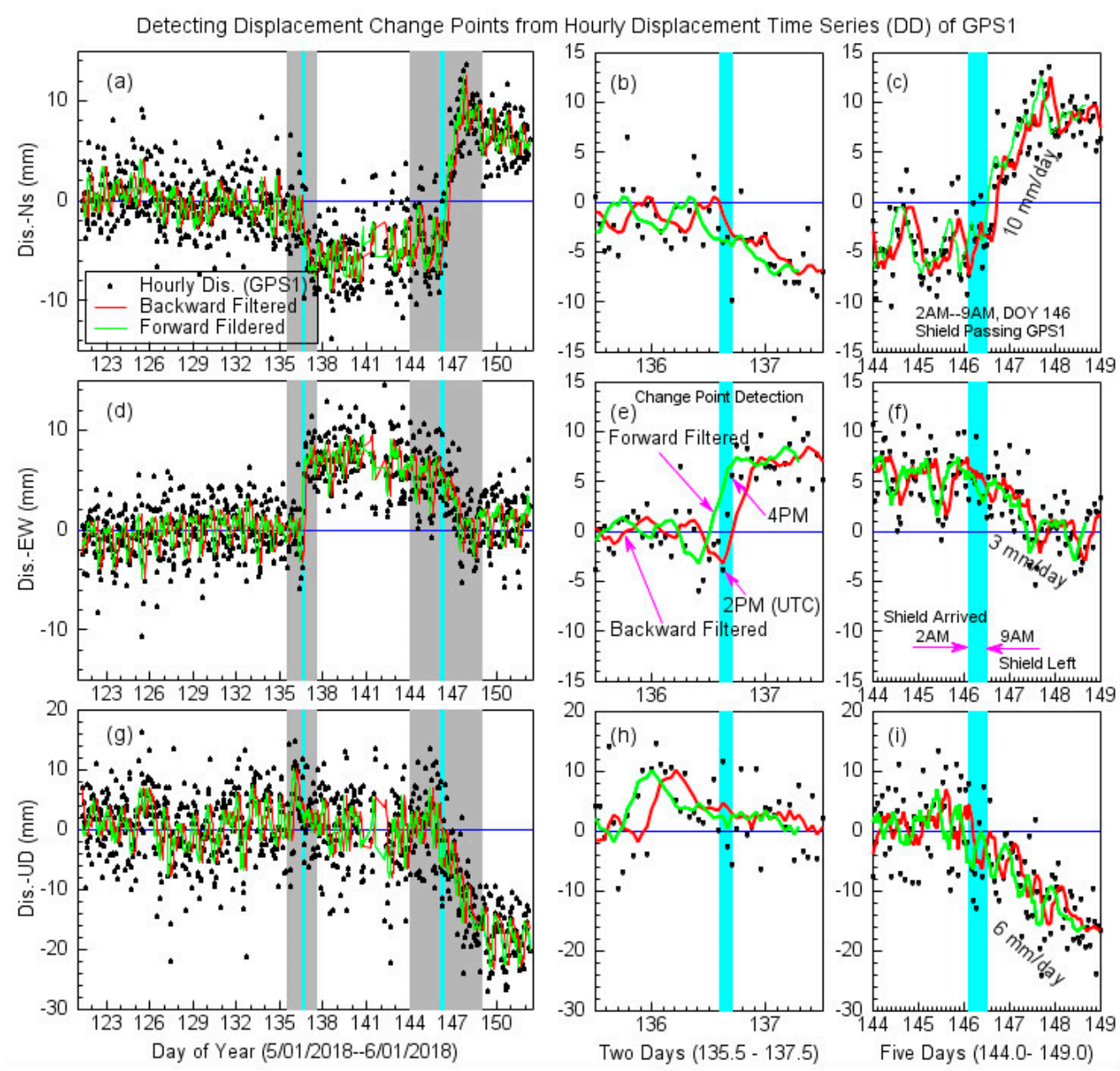

Figure 7. Plots demonstrating the implementation of the change point detection (CPD) algorithm to aid in detecting abrupt and gradual displacements superimposed into the hourly positional time series of GPS1.

\section{Results}

Ground settlement resulting from constructions of twin tunnels has been subjected to extensive investigations [43-46]. It is beyond the scope of this paper to speculate how excavation of the tunnel induced riverbed deformation, and how excavation of the second tunnel interacted with the first tunnel. However, a quick look at the displacement time series does give some impressive results that may help to understand the complexity of the riverbed deformation during shallow tunneling.

In order to track the riverbed displacements in the directions along and across the tunnel centerline, the previous horizontal EW-NS coordinate system was rotated by 63.7 degrees clockwise $\left(\theta=-63.7^{\circ}\right)$ to form an $\mathrm{X}-\mathrm{Y}$ coordinate system as shown in Figure 8.

$$
\mathrm{X}=\mathrm{EW} \times \sin \theta+\mathrm{NS} \times \cos \theta \mathrm{Y}=\mathrm{EW} \times \cos \theta-\mathrm{NS} \times \sin \theta
$$

After the rotation, the $\mathrm{X}$-axis is parallel to the excavation direction, and the $\mathrm{Y}$-axis is perpendicular to the excavation direction. The displacement time series with respect to the rotated coordinate system of these six rover antennas are illustrated in Figure 9. The displacements are derived from daily DD solutions referred to the base station. The dates that the shield passed the GPS sites are plotted on each subfigure. Those dates are also listed in Table 1. 
(a)

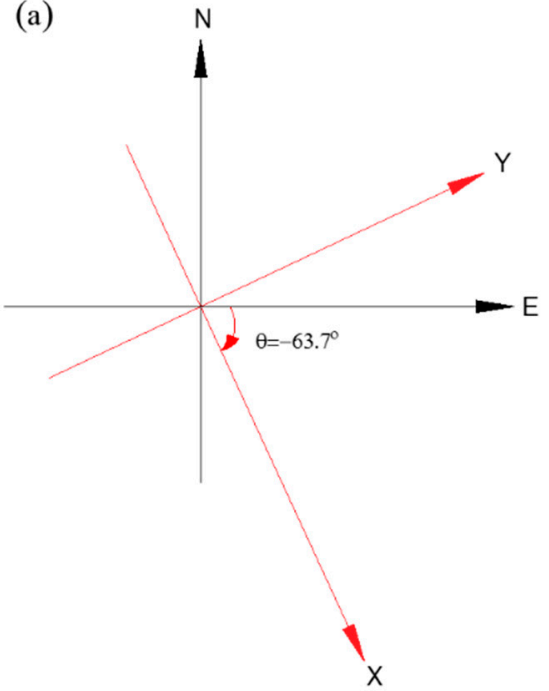

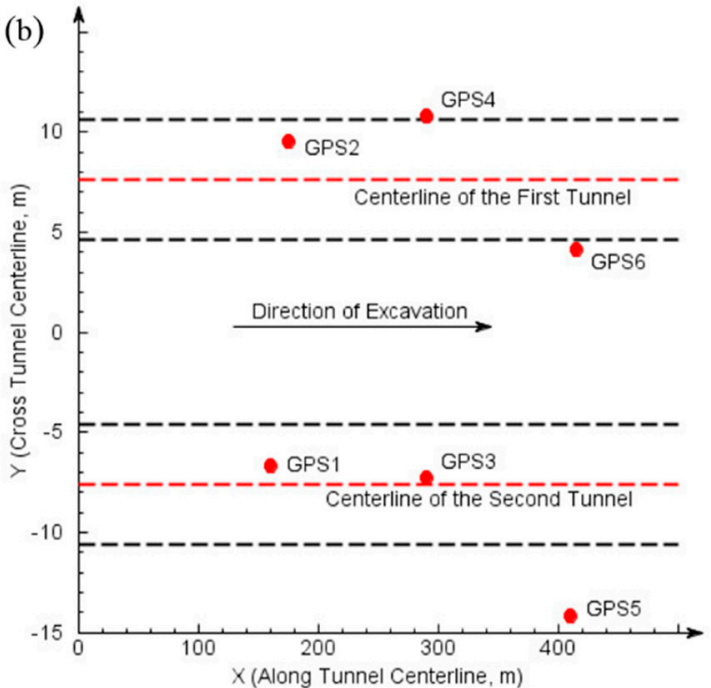

Figure 8. (a) The coordinate rotation from the EW-NS coordinates to the X-Y coordinates; (b) The X-axis aligns with the centerline of the tunnel, and the positive direction indicates the shield driven direction; the $\mathrm{Y}$-axis aligns with the lateral direction that is perpendicular to the tunnel centerline.
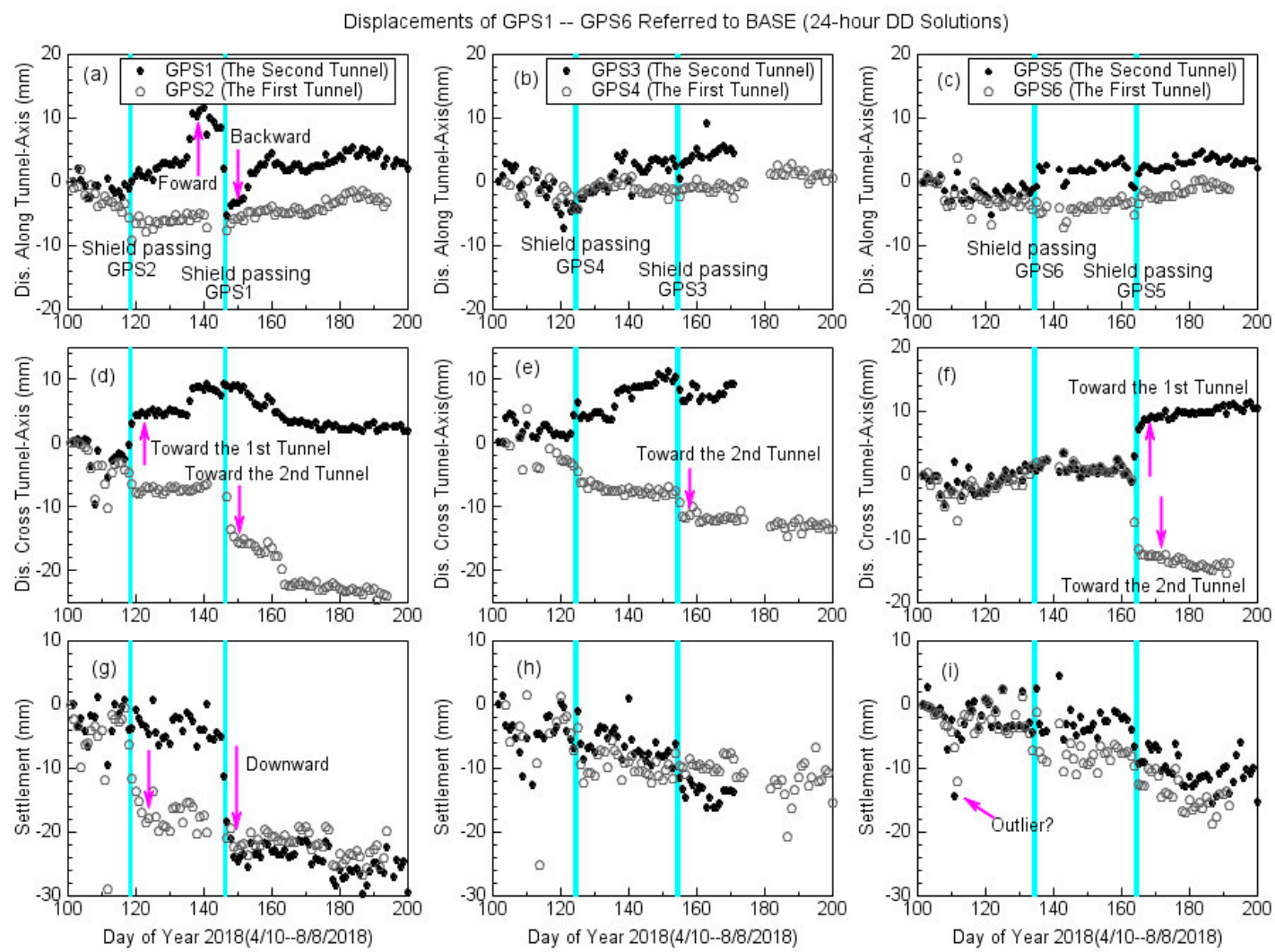

Figure 9. GPS-derived daily displacement time series at six rover GPS sites with respect to the base station. (a), (d), and (g) illustrate the displacement time series of GPS1 and GPS2 in the directions along tunnel-axis, cross tunnel-axis, and vertical, respectively; (b), (e), and (h) illustrate the displacement time series of GPS3 and GPS4 in the directions along tunnel-axis, cross tunnel-axis, and vertical, respectively; (c), (f), and (i) illustrate the displacement time series of GPS5 and GPS6 in the directions along tunnel-axis, cross tunnel-axis, and vertical, respectively.

The shield machine passed GPS2, GPS4, and GPS6 sites on 28 April, 4 May, and 15 May 2018, respectively, during the excavation of the first tunnel. Only GPS2 recorded an abrupt settlement 
of approximately $2 \mathrm{~cm}$ within one week after the shield passing this site. GPS4 and GPS6 did not record any considerable immediate settlement after the shield passing. The shield machine passed GPS1, GPS3, and GPS5 on 26 May, 4 June, and 13 June 2018, respectively, during the excavation of the second tunnel. GPS1 recorded an abrupt settlement of approximately $2.2 \mathrm{~cm}$ within four days after the shield passing. GPS3 and GPS5 recorded minor abrupt settlement of approximately $0.5 \mathrm{~cm}$ within one week after the shield passing. GPS2, GPS4, and GPS6 on the first tunnel did not record any considerable settlement during the excavation of the second tunnel. That means the vertical deformation of the riverbed induced by the second tunnel excavation was negligible in the area above the centerline of the first tunnel, which is $15.2 \mathrm{~m}(\sim 2.5 \mathrm{D})$ away from the centerline of the second tunnel. All sites show a slow gradual post-construction settlement with an average rate of approximately 3 to $5 \mathrm{~mm} / \mathrm{month}$ with respect to the base. Peck [47] observed that the settlement trough over a single tunnel could be represented within reasonable limits by a Gaussian distribution curve, which has become one of the simple and popularly used methods to predict soft ground settlements induced by shallow tunneling. The Peck-settlement-trough over a single tunnel can be estimated by the following formula $[47,48]$ :

$$
S(x)=S_{\max } \exp \left(-\frac{x^{2}}{2 i^{2}}\right)
$$

where $S(x)$ is the vertical settlement of a point which is at a distance of $x$ from the vertical plane containing the tunnel centerline; $S_{\max }$ is the maximum settlement value, the settlement of the point directly above the centerline of the tunnel; and $i$ is the horizontal distance from the tunnel centerline to the inflection point of settlement curve, which is also known as the half-width of the settlement trough. Researchers and engineers in China have recommended specific parameters for estimating the settlement in China based on their experience from urban shield-tunneling projects [49-52]. The width of the Gaussian curve (i) can be estimated by the following formula [47]:

$$
i=\frac{H}{\sqrt{2 \pi} \tan \left(45^{\circ}-\frac{\varphi}{2}\right)^{\prime}}
$$

where $H$ is the depth of the tunnel centerline; $\varphi$ is the internal friction angle of the ground, which is set as 25 degrees for this project. The $i$ value for the case study is $10.6 \mathrm{~m}$. The maximum settlement $\left(S_{\max }\right)$ at the riverbed can be estimated by the following formula:

$$
S_{\max }=\frac{\pi R^{2} \eta}{i \sqrt{2 \pi}}
$$

where $R$ is the radius of the tunnel; $\eta$ is the ratio of soil volume loss (usually expressed as a percentage), which can be estimated by the following formula [53]:

$$
\eta=1.303\left(\frac{H}{D}\right)^{-0.347}
$$

where $H$ is the depth of the tunnel centerline, and $D$ is the diameter of the tunnel.

For side-by-side twin tunnel construction, ground surface settlement and lining stress have increased influence from superimposition effects, as compared to the construction of a single-tunnel. It has been observed in many tunneling projects that surface settlement troughs caused by twin tunnels can have a variety of shapes, unlike single tunnels [44]. Figure 10 indicates that the settlements $(\sim 2 \mathrm{~cm})$ at GPS1 and GPS2 (Figure 9) are considerably larger than the predicted ones, while the settlements at other stations are comparable with predicted ones. The reasons causing large riverbed deformations at GPS2 and GPS1 will be further investigated in future studies. 


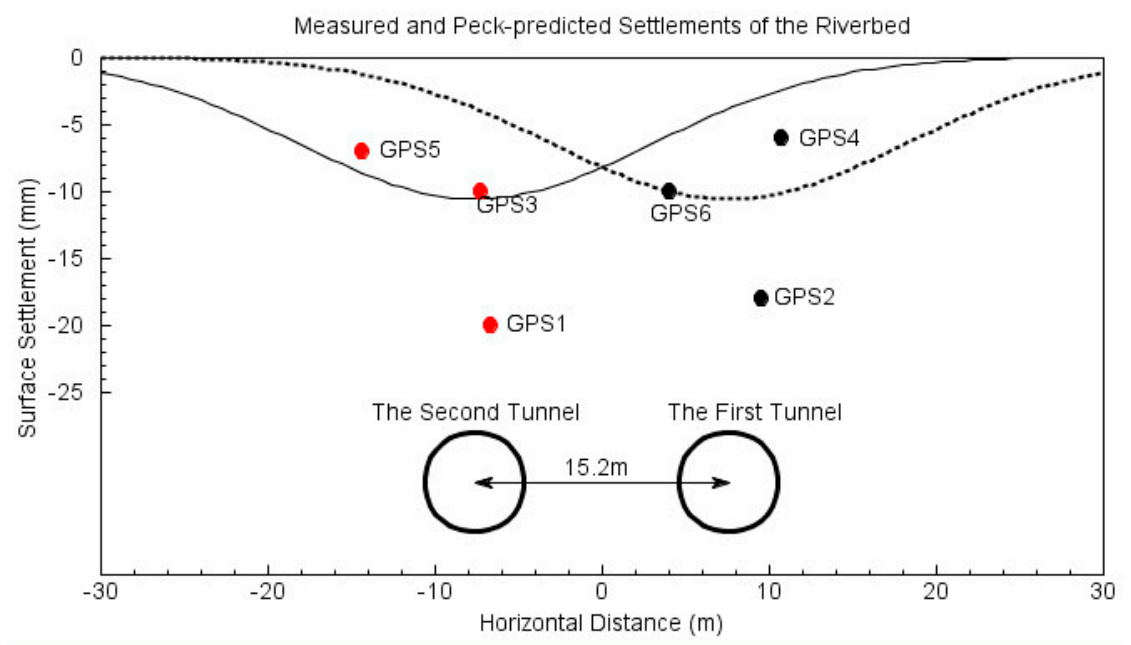

Figure 10. Comparisons of the GPS-measured and Peck-predicted settlements of the riverbed.

Figure $9 a, b, c$ exhibit the horizontal movement of six rover antennas along the tunnel centerline direction. GPS1 recorded a gradual forward movement up to one centimeter starting approximately ten days before the shield arrived at GPS1 (see Figure 7a,b for details); the riverbed began to move backward (rebound) immediately after the shield passed GPS1 and ultimately returned to its original place within one week. The horizontal forth and back movements along the excavation direction were not observed at other GPS sites. Figure 9d,e,f exhibit the horizontal movements of GPS along the lateral direction. GPS2 and GPS4 on the first tunnel showed a 5-mm lateral-shift when the shield passed each site. GPS6 did not show any considerable lateral movement. On the second tunnel, only GPS5 showed an 8-mm shift toward the first tunnel when the shield passed the site; GPS1 and GPS3 did not show any considerable lateral movements. However, GPS2, GPS4, and GPS6 on the first tunnel experienced 5- to $10-\mathrm{mm}$ horizontal movements toward the second tunnel during the excavation of the second tunnel.

Owing to the excavation of the second tunnel, an increase in the external load acting on the first tunnel is expected. The greater the tunnel distance, the lower the impact of the second tunnel on the normal force in the first tunnel. Previous investigations indicated that there is a negligible effect of interaction at the ground surface between twin tunnels if the distance between the tunnel centerlines is larger than two and half times the tunnel diameter (2.5 D), which is also called the critical distance $[43,45,54]$. The centerline-to-centerline distance of the two tunnels is $15.2 \mathrm{~m}$, slightly larger than the critical distance $(2.5 \times 6 \mathrm{~m})$. There was no considerable riverbed settlement beyond the critical distance. However, substantial horizontal riverbed movements $(\sim 1 \mathrm{~cm})$ toward the second tunnel were induced above the first tunnel during the excavation of the second tunnel. The observations presented in Figure 9 suggest that the general rule is only applicable to the vertical riverbed deformation. Three-component GPS measurements provide critical information for studying the interaction of twin tunnels in the horizontal directions, which has not been sufficiently investigated in previous studies because of a lack of horizontal measurements.

\section{Discussion}

During shallow tunnel excavations, the main objective of deformation monitoring is to detect minor abrupt-displacements as well as slow gradual-displacements and alert the excavation to prevent potential damages. As acceptable deformation levels are usually very low, accurate and reliable measurements are required and, very often, near real-time detection is needed. We introduced a static positioning approach that integrates PPP and short-baseline DD processing to achieve few-millimeter-accuracy for displacement measurements. The accuracy depends on the length of the observational sessions. Longer observational sessions often result in a higher accuracy but delay the identification of field events. In the practice of near real-time monitoring, a trade-off between 
timeliness and accuracy has to be considered. The magnitude of structural deformation is often minor and the process is often slow. As a consequence, it is difficult to identify minor displacement-steps by eye in near real-time. We introduced a CPD algorithm combining backward and forward average-filtering to aid in detecting minor abrupt-displacements. In practice, no CPD algorithm operates perfectly because it must inspect new data before determining if a change point occurred between the old and new data points. Incorporating variable observational sessions (e.g., every 15, $30 \mathrm{~min}$, one hour, one day) for static positioning and variable sliding-windows (e.g., $5+1$ points, $10+1$ points) for the CPD filtering may provide a better solution to identify and confirm the abrupt and gradual displacements in time.

The monitoring system introduced in this study was able to detect 5-mm and larger abrupt-deformations in near real-time and slow gradual-deformations at a couple of millimeters per day within a week. In general, the detection ability at this level would meet the requirement of most monitoring projects with the preliminary purpose of assessing the safety of structures. However, there are outliers that can cause certain problems in near real-time structural deformation monitoring using the GPS-only observations. Figure 9 indicates that there are several outliers in the GPS-derived displacement time series, particularly in the vertical component. The outliers can be identified and removed in post-processing by comparing with the overall datasets. However, it is a challenge to judge an incoming measurement that is further away from the mean as an outlier or as a real positional change. There is a wide range of possible reasons that lead to outliers in GPS-derived displacement time series. Some reasons are related to specific satellite signals at a specific epoch, such as multipath reflections, cycle clips, and satellite clock errors. An outlier occurring in GPS-derived displacement time series may not occur in the displacement time series derived from other satellite systems since the outlier could be satellite specific. Near real-time positioning results from BeiDou may provide a second thought to confirm or decline a potential displacement event obtained from GPS-only observations.

As of May 2019, there are more than 110 operational GNSS satellites in orbits, which comprises of approximately 31 GPS satellites, 33 BeiDou satellites, 25 GLONASS satellites, and 22 Galileo satellites. These 33 operational BeiDou satellites include 6 satellites in geostationary orbit (GEO), 6 satellites in 55-degree inclined geosynchronous orbits (IGSO), and 21 satellites in medium Earth orbits (MEO) (http://www.csno-tarc.cn). Furthermore, eight satellites (3 in MEO, 2 in GEO, 3 in IGSO) are undergoing testing or commissioning. The full BeiDou constellation will consist of 35 operational satellites and will be completed in 2020. A greater number of simultaneously visible satellites theoretically brings many advantages.

Numerous investigations have demonstrated that a multi-GNSS approach (e.g., GPS + BeiDou) is able to improve the performance of real-time-kinematic (RTK) positioning, particularly in urban and mountainous areas, where the lack of visible GPS satellite numbers and multipath reflections limit the performance of RTK [55-59]. However, it has been reported that multi-GNSS observations do not noticeably improve the accuracy of static positioning compared to GPS-only observations; somehow, using multi-GNSS observations can even degrade the accuracy of static positioning compared to using GPS-only observations [60-62]. Accordingly, we processed GPS and BeiDou observations separately in this study. Figure 11 depicts the comparisons of three-component displacement time series of GPS1 derived from GPS-only and BeiDou-only observations, respectively. The displacements are the 24-h DD solutions with respect to the base station. Similar to the DD processing for GPS that only used L1 (1575.420 MHz) observations, the DD processing for BeiDou only used B1(1561.098 MHz) observations. The time series depicted in Figure 11 indicates that the BeiDou-derived displacements retain slightly larger scatters than the GPS solutions. The GPS-derived displacements retain 1-mm horizontal RMS-accuracy and 2-mm vertical RMS-accuracy; the BeiDou-derived displacements retain 2-mm horizontal RMS-accuracy and 5-mm vertical RMS-accuracy. However, the trends from the two datasets agree well in delineating the displacements of the antenna over time. The back and forth movement of the ground surface along the excavation direction and the settlement during the excavation were 
observed from both GPS and BeiDou observations. Most outliers occurring in the GPS-derived displacement time series did not occur on the same days in the BeiDou-derived displacement time series. Thus, the BeiDou-only measurements are beneficial to distinguish real positional-changes from outliers which appeared in GPS-only measurements. By parallel processing GPS and BeiDou observations in near real-time, an abrupt positional shift can be detected with a higher confidence, thus minimizing false alerts.

(a) Displacements of GPS1 Referred to Base
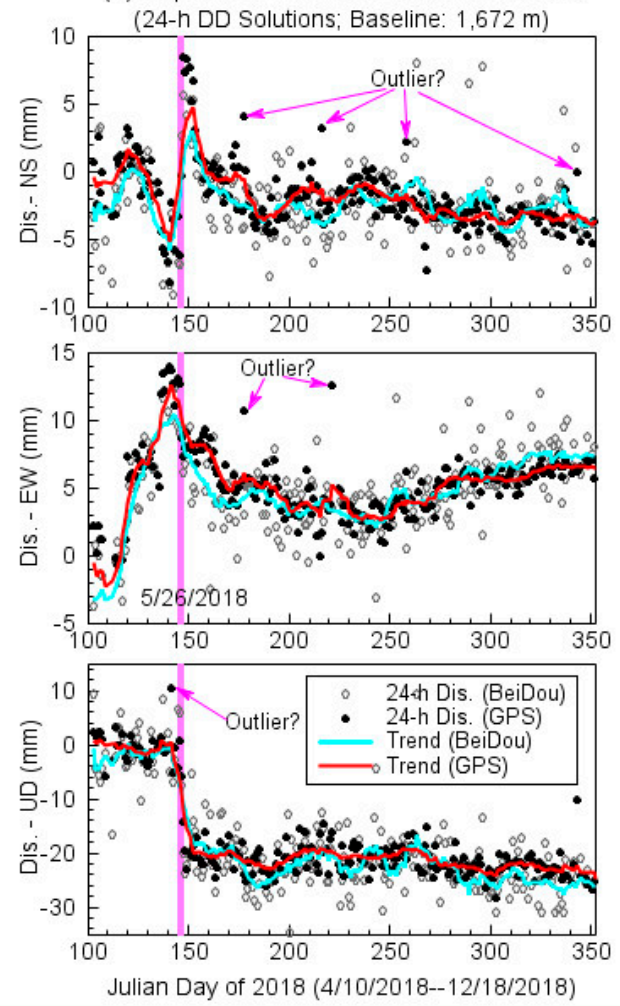

(b) Residuals of Measurements
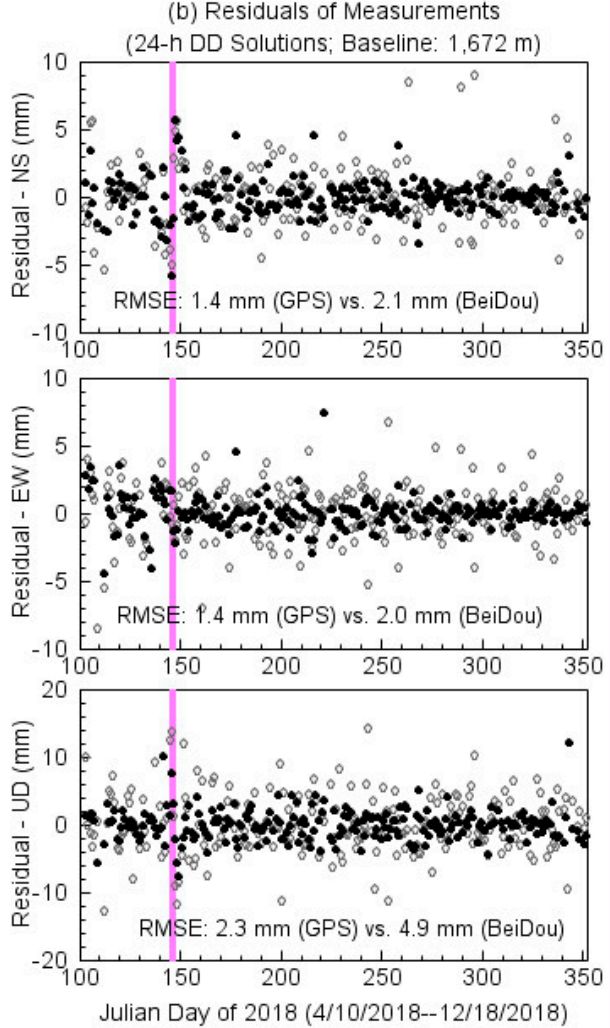

Figure 11. Comparisons of three-component displacement time series (GPS1) derived from GPS-only (L1) and BeiDou-only (B1) observations. The trend line is obtained by a moving average (unweighted) filter. The width of the sliding window is 11 points compromising the current point and five points before and after the current point.

There are various reasons to explain why the positional accuracy of BeiDou is below the accuracy of GPS. Figure 12 depicts two azimuth-elevation plots of phase residuals per satellite for station GPS1 on 8 May 2018. The scheme is often called "skyplot". The outer circle marks azimuths for the satellites and also indicates the horizon as seen from the station. The 90-degree elevation, directly above the station, is at the center of the circle. Thin red lines indicate the tracks of the GPS satellites during the 4-hour interval. The green traces along these lines are the time series of phase residuals (the mismatch between recorded and modeled satellite signal phases) for each satellite. Skyplots are an efficient tool to quickly assess the effects of multipath and water vapor. High residuals in the same place at different times most likely suggest multipath effects; high residuals appearing in a given place only at one time mostly suggest water vapor and other effects. The skyplots exhibited in Figure 12 indicate that the BeiDou signals were more seriously affected by multipath effects than GPS signals. The unique constellation design of BeiDou (GEO + IGSO + MEO) makes it more difficult to mitigate multipath effects compared to GPS (MEO only). The multipath issue of BeiDou signals has been intensively investigated recently [63-68]. It is expected that the algorithms for modeling multipath effects on BeiDou observations will be improved in the near future. 

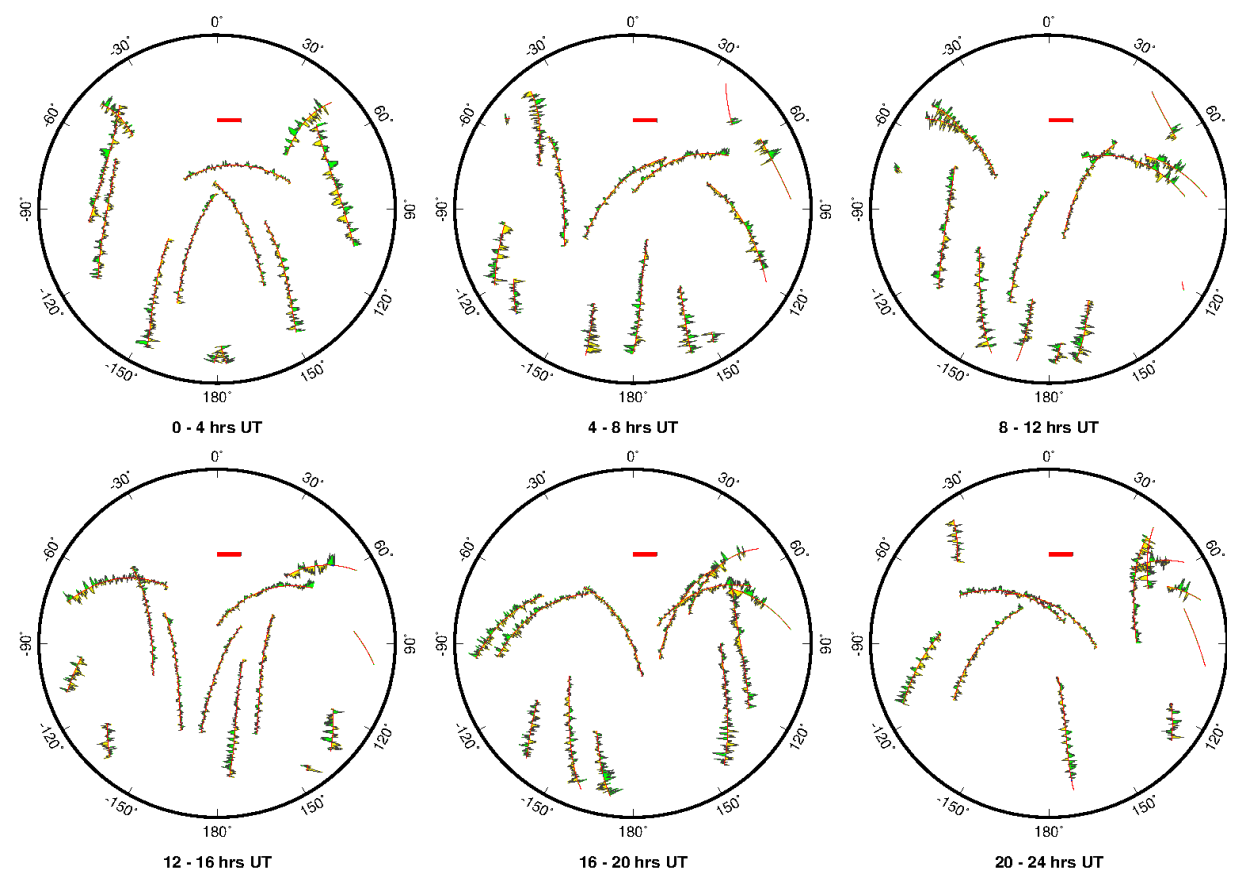

(a) Four-hour skyplots derived from GPS-only observations (GPS1, Day 128).
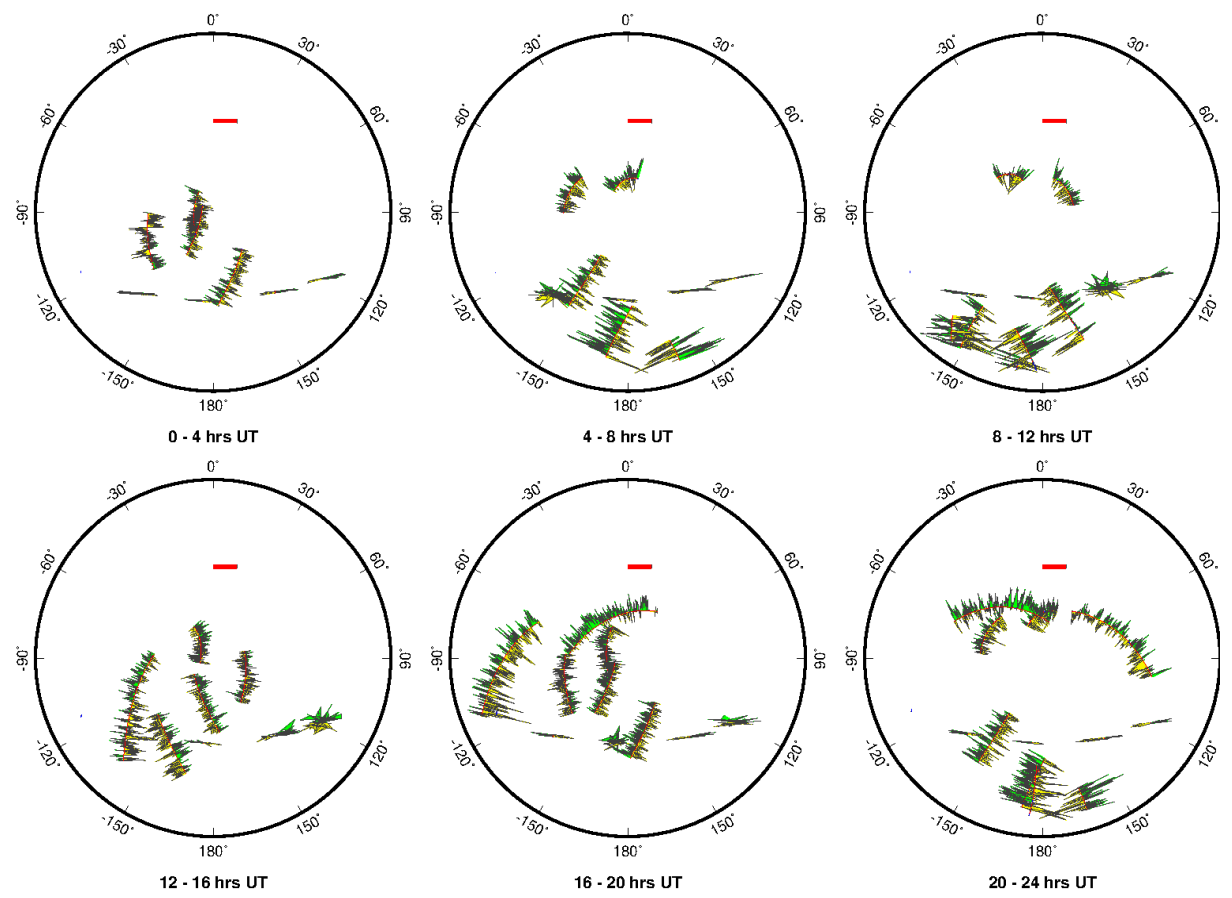

(b) Four-Hour skyplots derived from BeiDou-only observations (GPS1, Day 128).

Figure 12. The azimuth-elevation plots (skyplots) of phase residuals per satellite for station GPS1 on day 128, 8 May 2018.

The skyplots indicate that both GPS and BeiDou have approximately 7 to 11 visible satellites at GPS1. GPS satellites are equally distributed over the station, but more BeiDou satellites are distributed on the southern side due to these four GEO satellites. Due to the unequal distribution of BeiDou satellites in space, its geometric dilution of precision (GDOP) will be higher than the GDOP of GPS. GDOP is a term used in satellite navigation to specify the additional multiplicative effect of navigation satellite geometry on positional measurement precision. A higher GDOP may result in 
a poorer position. The visible number and the geometry of BeiDou satellites will be improved in 2019 and in the following years. It is expected that BeiDou observations will achieve similar or even better positional accuracy as GPS in China for static positioning in the near future.

\section{Conclusions}

This study developed a comprehensive method that integrates absolute and relative GPS positioning methods, a stable regional reference frame, a seasonal ground deformation model, and an automated CPD algorithm to monitor and detect riverbed deformation in near real-time and the long-term. The method is able to detect abrupt positional-changes as minor as five millimeters in near real-time and gradual positional-changes at a couple of millimeters per day within a week. The critical components of this method are:

1. Establishing a short-baseline GNSS network with one reference station and a group of rover stations fixed on monitoring objects;

2. Monitoring the long-term stability of the base station using PPP, a stable regional or local reference frame, and a seasonal ground deformation model;

3. Monitoring the movement of the rover antennas using the DD method in near real-time;

4. Applying an automated CPD algorithm to aid in detecting minor abrupt-displacements and slow gradual-displacements at both base and rover sites in near real-time.

This investigation indicates that BeiDou observations can also provide few-millimeter accuracy for structural deformational monitoring. Parallel processing BeiDou and GPS datasets will improve the reliability of near real-time monitoring and minimize false alerts. The method introduced in this article can be implemented for near real-time and long-term monitoring of critical structures, such as dams, large-span bridges, and high-rise buildings. It is expected that this study will promote the applications of high-accuracy GPS and BeiDou techniques in SHM.

Author Contributions: Y.B. managed the GPS network and conducted data analysis. W.G. and G.W. prepared the original draft. All authors participated in GPS network installation and operation, and edited, reviewed, and improved the manuscript.

Funding: This research was supported by the National Science Foundation of China (No. 51829801), the China Railway 17th Bureau Group Co., Ltd., the Key Laboratory of Urban Security and Disaster Engineering at the Beijing University of Technology, and the Key Laboratory of Soft Soil Engineering Character and Engineering Environment of Tianjin at the Tianjin Chengjian University.

Acknowledgments: The authors appreciate graduate students Shaohua Li and Kechao Wang at the Beijing University of Technology and technicians at the China Railway 17th Bureau Group Co., Ltd. for their assistance in installing and operating the GPS network.

Conflicts of Interest: The authors declare no conflict of interest.

\section{References}

1. Yi, T.-H.; Li, H.-N.; Gu, M. Experimental assessment of high-rate GPS receivers for deformation monitoring of bridge. Measurement 2013, 46, 420-432. [CrossRef]

2. Wang, J.; Meng, X.; Qin, C.; Yi, J. Vibration frequencies extraction of the forth road bridge using high sampling GPS data. Shock Vib. 2016, 2016, 1-18. [CrossRef]

3. Yigit, C.O.; Gurlek, E. Experimental testing of high-rate GNSS precise point positioning (PPP) method for detecting dynamic vertical displacement response of engineering structures. Geomat. Nat. Haz. Risk. 2017, 8, 893-904. [CrossRef]

4. Yu, J.; Yan, B.; Meng, X.; Shao, X.; Ye, H. Measurement of bridge dynamic responses using network-based real-time kinematic GNSS technique. J. Surv. Eng. 2016, 142. [CrossRef]

5. Tang, X.; Roberts, G.W.; Li, X.; Hancock, C.M. Real-time kinematic PPP GPS for structure monitoring applied on the Severn Suspension Bridge, UK. Adv. Space Res. 2017, 60, 925-937. [CrossRef]

6. Kaloop, M.; Elbeltagi, E.; Hu, J.; Elrefai, A. Recent advances of structures monitoring and evaluation using GPS time series monitoring systems: A review. ISPRS Int. J. Geo-Inf. 2017, 6, 382. [CrossRef] 
7. Meng, X.; Nguyen, D.T.; Xie, Y.; Owen, J.S.; Psimoulis, P.; Ince, S.; Chen, Q.; Ye, J.; Bhatia, P. Design and implementation of a new system for large bridge monitoring-GeoSHM. Sensors 2018, 18, 775. [CrossRef]

8. Xi, R.; Jiang, W.; Meng, X.; Zhou, X.; He, Q. Rapid initialization method in real-time deformation monitoring of bridges with triple-frequency BDS and GPS measurements. Adv. Space Res. 2018, 62, 976-989. [CrossRef]

9. Im, S.B.; Hurlebaus, S.; Kang, Y.J. Summary review of GPS technology for structural health monitoring. J. Struct. Eng. 2013, 139, 1653-1664. [CrossRef]

10. Montillet, J.-P.; Szeliga, W.M.; Melbourne, T.I.; Flake, R.M.; Schrock, G. Critical infrastructure monitoring with Global Navigation Satellite Systems. J. Surv. Eng. 2016, 142. [CrossRef]

11. Bao, Y.; Guo, W.; Wang, G.; Gan, W.; Zhang, M.; Shen, S. Millimeter-accuracy structural deformation monitoring using stand-alone GPS: Case study in Beijing, China. J. Surv. Eng. 2018, 144. [CrossRef]

12. Li, H.N.; Li, D.S.; Song, G. Recent application of fiber optic sensors to health monitoring in civil engineering. Eng. Struct. 2004, 26. [CrossRef]

13. Farrar, C.; Worden, K. An introduction to structural health monitoring. Phil. Trans. R. Soc. 2007, 365, $303-315$. [CrossRef] [PubMed]

14. Song, G.; Wang, C.; Wang, B. Structural health monitoring (SHM) of civil structures. Appl. Sci. 2017, 7, 789. [CrossRef]

15. Sony, S.; Laventure, S.; Sadhu, A. A literature review of next-generation smart sensing technology in structural health monitoring. Struct. Control Health Monit. 2019, 26. [CrossRef]

16. Zhu, H.H.; Xu, Q.W.; Liao, S.M.; Fu, D.M.; Yu, N. Experimental study on working parameters of EPB shield machine. Chin. J. Geotech. Eng. 2006, 28, 553-557. (In Chinese)

17. Chen, R.P.; Zhu, J.; Liu, W.; Tang, X.W. Ground movement induced by parallel EPB tunnels in silty soils. Tunn. Undergr. Sp. Tech. 2011, 26, 163-171. [CrossRef]

18. Li, X.; Yuan, D.; Guo, Y.; Cai, Z. Use of a $10.22 \mathrm{~m}$ diameter EPB shield: A case study in Beijing subway construction. Springerplus 2016, 5, 2004. [CrossRef]

19. Li, P.F.; Chen, K.Y.; Wang, F.; Li, Z. An upper-bound analytical model of blow-out for a shallow tunnel in sand considering the partial failure within the face. Tunn. Undergr. Sp. Tech. 2019, 91. [CrossRef]

20. Su, X.; Xu, W.; Du, S. Responses of groundwater vulnerability to artificial recharge under extreme weather conditions in Shijiazhuang City, China. J. Water Supply Res. T. 2014, 63, 224-238. [CrossRef]

21. Wang, G.; Philips, D.; Joyce, J.; Rivera, F. The integration of TLS and continuous GPS to study landslide deformation: A case study in Puerto Rico. J. Geod. Sci. 2011, 1, 25-34. [CrossRef]

22. Wang, G. Kinematics of the Cerca del Cielo, Puerto Rico landslide derived from GPS observations. Landslides 2011, 9, 117-130. [CrossRef]

23. Liu, H.; Wang, G. Relative motion between St. Croix and the Puerto Rico-Northern Virgin Islands mlock derived from continuous GPS observations (1995-2014). Int. J. Geophysics 2015, 2015, 1-9. [CrossRef]

24. Yang, L.; Wang, G.; Huérfano, V.; von Hillebrandt-Andrade, C.G.; Martínez-Cruzado, J.A.; Liu, H. GPS geodetic infrastructure for natural hazards study in the Puerto Rico and Virgin Islands region. Nat. Hazards 2016, 83, 641-665. [CrossRef]

25. Liu, Y.; Sun, X.; Wang, G.; Turco, M.J.; Agudelo, G.; Bao, Y.; Zhao, R.; Shen, S. Current activity of the Long Point Fault in Houston, Texas constrained by continuous GPS measurements (2013-2018). Remote Sens. 2019, 11, 1213. [CrossRef]

26. Wang, G.; Boore, D.M.; Tang, G.; Zhou, X. Some observations on colocated and closely spaced 1-second sampled GPS and ground-motion accelerograph data from the 2003 San Simeon (M6.5), California, earthquake. Seism. Soc. Am. 2007, 97, 76-90. [CrossRef]

27. Wang, G.; Blume, F.; Meertens, C.; Ibanez, P.; Schulze, M. Performance of high-rate kinematic GPS during strong shaking: Observations from shake table tests and the 2010 Chile earthquake. J. Geod. Sci. 2012, 2. [CrossRef]

28. Wang, G. GPS Landslide Monitoring: Single Base vs. Network Solutions-A case study based on the Puerto Rico and Virgin Islands Permanent GPS Network. J. Geod. Sci. 2011, 1. [CrossRef]

29. Wang, G. Millimeter-accuracy GPS landslide monitoring using Precise Point Positioning with Single Receiver Phase Ambiguity (PPP-SRPA) resolution: A case study in Puerto Rico. J. Geod. Sci. 2013, 3. [CrossRef]

30. Wang, G.; Bao, Y.; Cuddus, Y.; Jia, X.; Serna, J.; Jing, Q. A methodology to derive precise landslide displacement time series from continuous GPS observations in tectonically active and cold regions: A case study in Alaska. Nat. Hazards 2015, 77, 1939-1961. [CrossRef] 
31. Wang, G.; Turco, M.; Soler, T.; Kearns, T.J.; Welch, J. Comparisons of OPUS and PPP solutions for subsidence monitoring in the greater Houston area. J. Surv. Eng. 2017, 143. [CrossRef]

32. Wang, G.; Liu, H.; Mattioli, G.; Miller, M.; Feaux, K.; Braun, J. CARIB18: A stable geodetic reference frame for geological hazard monitoring in the Caribbean region. Remote Sensing 2019, 11, 680. [CrossRef]

33. Geng, J.; Meng, X.; Dodson, A.H.; Teferle, F.N. Integer ambiguity resolution in precise point positioning: Method comparison. J. Geod. 2010, 84. [CrossRef]

34. Zumberge, J.F.; Heflin, M.B.; Jefferson, D.C.; Watkins, M.M.; Webb, F.H. Precise point positioning for the efficient and robust analysis of GPS data from large networks. J. Geophys. Res. Solid Earth 1997, 102, 5005-5017. [CrossRef]

35. Herring, T.A.; King, R.W.; Floyd, M.A.; Mcclusky, S.C. Introduction to GAMIT/GLOBK, Release 10.7; Massachusetts Institute of Technology: Cambridge, MA, USA, 2018.

36. Bertiger, W.; Desai, S.D.; Haines, B.; Harvey, N.; Moore, A.W.; Owen, S.; Weiss, J.P. Single receiver phase ambiguity resolution with GPS data. J. Geod. 2010, 84, 327-337. [CrossRef]

37. Wang, G.; Bao, Y.; Gan, W.; Geng, J.; Xiao, G.; Shen, J.S. NChina16: A stable geodetic reference frame for geological hazard studies in North China. J. Geodyn. 2018, 115, 10-22. [CrossRef]

38. Rebischung, P.; Altamimi, Z.; Ray, J.; Garayt, B. The IGS contribution to ITRF2014. J. Geod. 2016, 90, 611-630. [CrossRef]

39. Davis, J.L.; Wernicke, B.P.; Tamisiea, M.E. On seasonal signals in geodetic time series. J. Geophys. Res. Solid Earth 2012, 117. [CrossRef]

40. Aminikhanghahi, S.; Cook, D.J. A survey of methods for time series change point detection. Knowl. Inf. Syst. 2017, 51, 339-367. [CrossRef]

41. Truong, C.; Oudre, L.; Vayatis, N. A Review of Change Point Detection Methods. 2018. Available online: https://arxiv.org/pdf/1801.00718.pdf (accessed on 1 June 2019).

42. Wang, G.; Soler, T. Using OPUS for measuring vertical displacements in Houston, Texas. J. Surv. Eng. 2013, 139, 126-134. [CrossRef]

43. Do, N.A.; Dias, D.; Oreste, P.; Djeran-Maigre, I. 2D numerical investigations of twin tunnel interaction. Geomech. Eng. 2014, 6. [CrossRef]

44. Suwansawat, S.; Einstein, H. Describing settlement troughs over twin tunnels using a superposition technique. J. Geotech. Geoenviron. 2007, 133, 445-468. [CrossRef]

45. Vinod, M.; Khabbaz, H. Comparison of rectangular and circular bored twin tunnels in weak ground. Undergr. Sp. 2019. [CrossRef]

46. Zhao, W.; Jia, P.J.; Zhu, L.; Cheng, C.; Han, J.; Chen, Y.; Wang, Z.G. Analysis of the additional stress and ground settlement induced by the construction of double-o-tube shield tunnels in sandy soils. Appl. Sci. 2019, 9, 1399. [CrossRef]

47. Peck, R.B. Deep excavations and tunneling in soft ground. In Proceedings of the 7th International Conference on Soil Mechanics and Foundation Engineering, Mexico City, Mexico, 1969; State of the Art Volume. pp. 225-290. Available online: https://www.issmge.org/uploads/publications/1/38/1969_03_0010.pdf (accessed on 3 April 2019).

48. O'Reilly, M.P.; New, B.M. Settlements above Tunnels in the United Kingdom-Their Magnitude and Prediction; Tunneling 82; Institute of Mining and Metallurgy: London, UK, 1982; pp. 173-181.

49. Duan, S.; Huang, L.; Bao, Z.; Shen, P. Application of modified Peck formula in surface subsidence prediction of Changsha subway tunnel construction. J. Nat. Disasters 2015, 24, 164-169. [CrossRef]

50. Huang, L.; Duan, S.; Xie, Z.; Jiang, X. A revision of peck formula based on the surface subsidence due to metro excavation in Changsha. Electron. J. Geotech. Eng. 2015, 20, 2115-2123.

51. Zhu, C. Control of surface settlement by considering shield tunneling technology. KSCE J. Civ. Eng. 2017, 21, 2896-2907. [CrossRef]

52. Fang, Y.; He, C.; Nazem, A.; Yao, Z.; Grasmick, J. Surface settlement prediction for EPB shield tunneling in sandy ground. KSCE J. Civ. Eng. 2017, 21, 2908-2918. [CrossRef]

53. Liu, J.; Ding, W.; Dai, Z.; Wang, H.; Jia, K. Analysis of ground loss and its factors induced by EPB shield tunnel construction. J. Chongqing Jianzhu Uni. 2017, 39, 1-C8. [CrossRef]

54. Hefny, A.M. Parametric studies on the interaction between existing and new bored tunnels. Tunn. Undergr. Sp. Tech. 2004, 19. [CrossRef] 
55. Cai, C.; Gao, Y.; Pan, L.; Zhu, J. Precise point positioning with quad-constellations: GPS, BeiDou, GLONASS and Galileo. Adv. Space Res. 2015, 56, 133-143. [CrossRef]

56. Li, X.; Ge, M.; Dai, X.; Ren, X.; Fritsche, M.; Wickert, J.; Schuh, H. Accuracy and reliability of multi-GNSS real-time precise positioning: GPS, GLONASS, BeiDou, and Galileo. J. Geod. 2015, 89, 607-635. [CrossRef]

57. Rabbou, M.A.; El-Rabbany, A. PPP accuracy enhancement using GPS/GLONASS observations in kinematic mode. Positioning 2015, 6, 1-6. [CrossRef]

58. Yu, X.; Gao, J. Kinematic precise point positioning using multi-constellation Global Navigation Satellite System (GNSS) observations. ISPRS Int. J. Geo-Inf. 2017, 6, 6. [CrossRef]

59. Shi, C.; Zheng, F.; Lou, Y.; Gu, S.; Zhang, W.; Dai, X.; Li, X.; Guo, H.; Gong, X. National BDS Augmentation Service System (NBASS) of China: Progress and assessment. Remote Sens. 2017, 9, 837. [CrossRef]

60. Mohammed, J.; Moore, T.; Hill, C.; Bingley, R.M.; Hansen, D.N. An assessment of static precise point positioning using GPS only, GLONASS only, and GPS plus GLONASS. Measurement 2016, 88, 121-130. [CrossRef]

61. Alcay, S.; Yigit, C. Network based performance of GPS-only and combined GPS/GLONASS positioning under different sky view conditions. Acta Geod. Geophys. 2017, 52, 345-356. [CrossRef]

62. Msaewe, H.A.; Hancock, C.M.; Psimoulis, P.A.; Roberts, G.W.; Bonenberg, L.; de Ligt, H. Investigating multi-GNSS performance in the UK and China based on a zero-baseline measurement approach. Measurement 2017, 102, 186-199. [CrossRef]

63. Wang, M.; Chai, H.; Liu, J.; Zeng, A. BDS relative static positioning over long baseline improved by GEO multipath mitigation. Adv. Space Res. 2015, 57, 782-793. [CrossRef]

64. Dai, W.; Shi, Q.; Cai, C. Characteristics of the BDS carrier phase multipath and its mitigation methods in relative positioning. Sensors 2017, 17, 796. [CrossRef]

65. Lei, W.Y.; Wu, G.C.; Tao, X.X.; Bian, L.; Wang, X.L. BDS satellite-induced code multipath: Mitigation and assessment in new-generation IOV satellites. Adv. Space Res. 2017, 60, 2672-2679. [CrossRef]

66. Chen, X. Statistical multipath model comparative analysis of different GNSS orbits in static urban canyon environment. Adv. Space Res. 2018, 62, 1034-1048. [CrossRef]

67. Zhang, Q.; Yang, W.; Zhang, S.; Liu, X. Characteristics of BeiDou navigation satellite system multipath and its mitigation method based on Kalman filter and Rauch-Tung-Striebel smoother. Sensors 2018, 18, 198. [CrossRef] [PubMed]

68. Ge, Y.; Yang, X.; Qin, W.; Yang, H.; Guang, W.; Zhou, F.; Ouyang, M.; Wang, S. Mitigation of the multipath effect in BDS-based time transfer using a wave-absorbing shield. Adv. Space Res. 2019, 63, 2771-2783. [CrossRef]

(C) 2019 by the authors. Licensee MDPI, Basel, Switzerland. This article is an open access article distributed under the terms and conditions of the Creative Commons Attribution (CC BY) license (http://creativecommons.org/licenses/by/4.0/). 